\title{
LA ADORACIÓN DE LOS PASTORES EN LA PINTURA BARROCA CORDOBESA
}

\author{
JOSÉ MARÍA PALENCIA CEREZO \\ Museo de Bellas Artes de Córdoba
}

\begin{abstract}
Resumen
Como asunto preferente de la historia del cristianismo, la Adoración de los pastores a Jesús de Nazaret, será una de las temáticas más presentes en los distintos espacios religiosos de la ciudad de Córdoba, y también una de las predilectas de los pintores cordobeses del siglo XVII, que la cultivaron de manera profusa.

El estudio conjunto de las que han llegado hasta nuestro tiempo, bien procedentes de afuera, o bien salidas de los talleres de los principales artistas que trabajaron en la ciudad en ese periodo, permiten conocer perfectamente cómo evolucionó el gusto sobre este asunto bajo el signo del naturalismo barroco.
\end{abstract}

Palabras Clave

Pintura, Barroco, Córdoba, Adoración de los pastores.

\section{THE ADORATION OF THE SHEPHERDS IN THE BAROQUE PAINTING OF CORDOBA}

\begin{abstract}
As a matter of preference in the history of Christianity, the Adoration of the Shepherds to Jesus of Nazareth will be one of the most present themes in the different religious spaces of the city of Cordoba, and also one of the favorites of the Cordovan painters of the XVII century, who cultivated it profusely.

The joint study of those that have reached our time, either from the outside or from the workshops of the main artists who worked in the city during that period, let us know perfectly how the taste on this subject evolved throughout Of the time under baroque naturalism.
\end{abstract}

\section{Keywords}

Painting, Baroque, Córdoba, Adoration of the shepherds.

El estudio de la temática de la Adoración de los pastores en la pintura barroca cordobesa, no es nuevo, ni ha estado falto de preocupación por parte de los principales historiadores del 
arte local de la segunda mitad del siglo XX. De hecho, constituyó un tema específico de tratamiento de personalidades como Dionisio Ortiz Juárez (1913-1986) ${ }^{1}$, José Valverde Madrid (1913-2003) ${ }^{2}$, o Francisco Zueras Torrens (1918-1992) ${ }^{3}$. De una manera u otra, ellos abordaron la cuestión introduciendo sus propios juicios de autor y época sobre determinadas obras, a veces con acierto y otras no. No obstante, en cuanto se refiere a su desarrollo temporal, y en determinados casos, sobre la autoría de las obras que trataron, dejaron problemas sin resolver. Lo que dio lugar a que los estudiosos contemporáneos se sintiesen un tanto "desorientados" a la hora de acercarse a las obras tratadas, generando cierto panorama de confusión en base a la repetición de tópicos heredados, en muchos casos en contra de la propia lógica histórica.

Más recientemente, con motivo de la celebración en Córdoba del IV Centenario del nacimiento de Antonio del Castillo, el tema fue objeto de un apartado en la exposición Antonio del Castillo en la senda del naturalismo, comisariada por Fuensanta García de la Torre y Benito Navarrete Prieto, en la que se expusieron cuatro obras, no habiéndose tratado el tema con la amplitud que aquí se hace ${ }^{4}$.

Por mi parte, a fines de la década de 1990, en función de los datos certeros de los que era conocedor, me preocupé por tratar de resolver el problema, poniendo algo de lógica sobre cuestiones heredadas e insuficientemente resueltas, que hacían depender excesivamente a la pintura barroca cordobesa de la influencia de Francisco de Zurbarán. Redacté entonces el que ha sido hasta hoy mi primer trabajo respecto a un tema que, por lo general, tampoco ha sido muy abordado por otros historiadores, centrándome en las obras que se venían relacionando con el taller de los Ruiz de Saravia, uno de los obradores más activos entre los varios existentes en la ciudad en el siglo XVII ${ }^{5}$.

A lo largo de ese periodo, la pintura cordobesa no solo producirá destacados artífices, como Antonio del Castillo, -por lo demás, bastante bien conocido-, sino también a otros pintores significativos y no menos importantes, como Juan Luis Zambrano, José Ruiz de Saravia, Juan de Alfaro o Antonio Palomino. La mayoría de estos permanecen todavía hoy no suficientemente estudiados; sin embargo, todos contribuirían a que la pintura cordobesa alcanzase altas cumbres, situándose, respecto a Andalucía, tras la realizada en los núcleos principales de Sevilla y Granada.

\section{Las primeras Adoraciones llegadas a Córdoba: José de Ribera}

Dentro de la temática, las primeras obras de cierta importancia para la pintura local, se pueden localizar en Córdoba hacia 1630. Una fecha un tanto tardía si tenemos en cuenta que, por entonces, habría transcurrido ya un cuarto de siglo. La razón de tal situación tal vez estribe en la circunstancia de que Pablo de Céspedes (Hac.1547-1608), parece que no realizó, al menos en España, ninguna obra significativa con este asunto. Como es conocido, al igual que Francisco Pacheco, Céspedes jugó un papel importantísimo en la trasmisión de motivos iconográficos a la pintura barroca andaluza. Pero su temprana muerte en 1608, mermó la posibilidad de que nuestra pintura hubiese cogido diferente rumbo. A diferencia de otras iconografías, -como por ejemplo la de La última cena-, de él solo conocemos la Adoración de los

${ }^{1}$ Ortiz Juárez, 1960; 1961.

${ }^{2}$ Valverde Madrid, 1963:9-60.

3Zueras, 1987.

${ }^{4}$ García de la Torre y Navarrete Prieto, 2016: 45-98.

5Palencia, 2001:101-121.Una excepción a esta afirmación, a nivel de Andalucía, pueden ser los trabajos dedicados al tema por el profesor Valiñas López. De hecho, varias de las que aquí tratamos, sin variar un ápice lo que de ellas se venía diciendo, entraron a formar parte de su tesis doctoral, dirigida por el doctor Domingo Sánchez-Mesa Martín y defendida en 2005 en el Departamento de Historia del Arte de la Universidad de Granada. Véase, Valiñas López, 2005. 


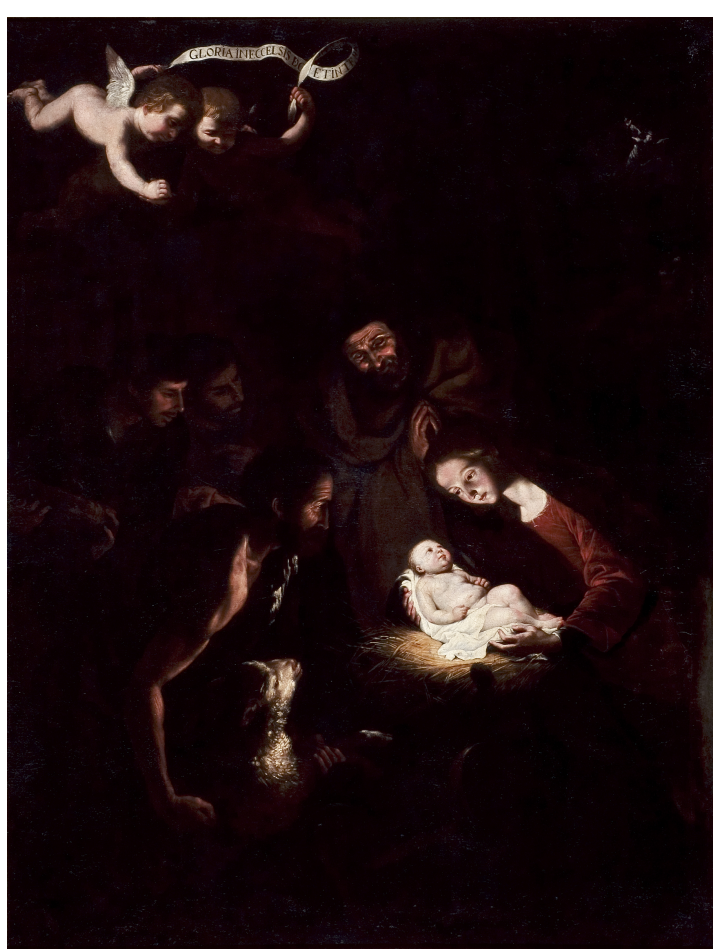

Fig. 1. Juan Do. Aquí atribuido. Adoración. Museo de Bellas Artes de Córdoba.

pastores que pintó hacia 1565 sobre los muros de la capilla de Antico Bonfilio en la Iglesia de Santa Trinidad del Monte en Roma, que a pesar de su majestuosidad y del magnífico bodegón de vestimentas pastoriles realizado en su lado inferior izquierdo, no parece que llegara a tener repercusión en este ámbito.

Esta falta de modelos, junto a la salida de Córdoba de sus principales discípulos, entre los que podemos considerar a Antonio Mohedano de la Gutierra (Hac.1563-1626), o a Juan de Peñalosa y Sandoval (1579-1633), -el primero hacia Antequera (Málaga) y el segundo a Astorga (León)-, dejaría libre el camino para que se pudiesen hacer con el mercado local otros pintores foráneos. Entre ellos destacaría uno de padre sevillano y oriundo de Morón de la Frontera; y otro extremeño de Azuaga (Badajoz), que contrae matrimonio en 1613 con una cordobesa, para ser el origen de la más grande dinastía de pintores locales. Me refiero concretamente a Juan Luis Zambrano (Hac.1598 - 1639) y a Agustín del Castillo (Hac.1565 $-1631)$.

Pero el pintor que va a ejercer una mayor influencia a lo largo del primer cuarto de la centuria va a ser sin duda el valenciano afincado en Nápoles José de Ribera (1591-1652). Así, en el Museo de Bellas Artes de Córdoba existen dos obras que se pueden relacionar con su actividad, confirmando esta tendencia. La primera de ellas es un lienzo $(123,5 \times 94 \mathrm{~cm}$.) de fuerte atmósfera clarooscurista, que todavía no ha sido restaurado modernamente. Al mismo ya se habría referido Antonio Ponz, que lo creía un probable original de Antonio del Castillo, como existente el la sacristía del Convento de San Agustín, afirmando que estaba muy deteriorado ${ }^{6}$. No obstante, en el XIX se vislumbró su relación con Ribera, al que estuvo atribuido en el Museo durante mucho tiempo. (Fig.1) Enrique Romero de Torres, - su director entre 1895 y 1943 -, lo creía copia de un original ubicado en la iglesia mayor de Vergara; aunque hoy sabemos, no solo que la obra de Vergara no llegó allí hasta 1658, sino que tanto ésta como la del Museo son réplicas de un óvalo $(182 \times 165 \mathrm{~cm})$ firmado por Ribera en 1630, que habría pasado por distintas colecciones europeas, incluida la del húngaro de origen judío Marcel Nemes (1866-1930). En esta última se conservó hasta 1918, en que fue subastada en

\footnotetext{
6 Ponz, 1792: 52.
} 
Fig. 2. José de Ribera. Adoración. 1630 Antigua colección Nemes.

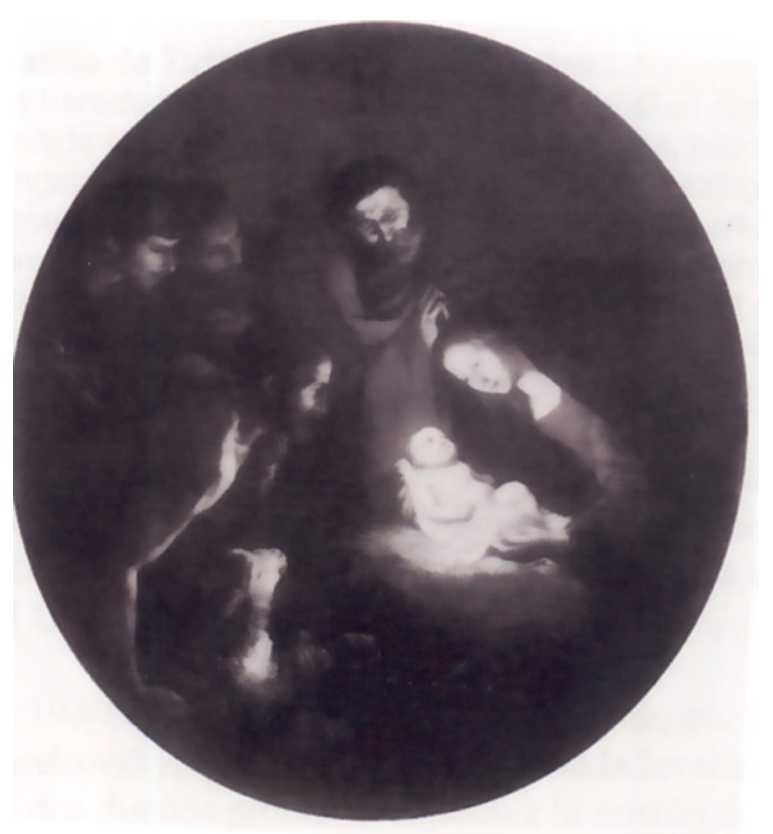

el Hotel Droulot de París, desconociéndose hoy su exacto paradero ${ }^{7}$. Respecto a este primer original, a la obra cordobesa solo se le habrían añadido dos angelitos sobrevolando por la zona iluminada en el ángulo superior izquierdo. (Fig.2)

A ella nos referimos en 2001, viéndola inspirada en dos estampas diferentes: una de Cornelio Cort que recoge una composición de Federico Zuccaro, y otra de Abraham Bloemaert $^{8}$. A ello añadimos ahora que debió de servirle de trabajo preparatorio el dibujo de Ribera que se conserva en el Museo Nacional de Liverpool, donde, a pesar de su forma apaisada, aparecen, en idénticas posiciones, los tres pastores, el cordero en primer plano y María sosteniendo al Niño. Solo variará el lugar que ocupa José, con mucha mayor presencia en el dibujo.(Fig.3) Siendo así, en su reciente catalogación de los dibujos de Ribera, Gabriele Finaldi, a pesar de hacer hincapié en que muestra la combinación de carboncillo y sanguina propia de los dibujos del maestro de mediados de la década de 1620, por desconocimiento de la obra de la colección Nemes, y por haberla relacionado solo con la Adoración de Ribera perteneciente al Monasterio de El Escorial, no parece haber acertado en la datación de este dibujo, pues lo considera realizado en la década de $1640^{\circ}$.

En relación a las diversas composiciones pastoriles efectuadas por Ribera, con respecto a este lienzo puede hablarse de un modelo simplificado o pequeño, que supo transmitir a sus discípulos, siendo la base de múltiples obras, como la que se atribuye a Bartolomé Pasante el antiguo Maestro del Anuncio a los pastores-, en la pintura homónima que se encuentra en el Museo de Birmingham.

La segunda obra de influencia riberesca localizada en Córdoba es otra Adoración (275 x $260 \mathrm{~cm}$.) que guarda igualmente el Museo de Bellas Artes como procedente del antiguo convento de San Francisco del Monte, sito entre los términos municipales de Villafranca y Adamuz. En el inventario efectuado por Enrique Romero de Torres a comienzos del siglo XX se la considera de Valdés Leal, creyéndosela tal vez copia de un original existente en la catedral de Valencia destruido en 1936. A pesar del mal estado de conservación que presenta, tras haber superado en nuestros días la fase número uno de la conservación preventiva, podemos afirmar que se trata de una obra, si no copia propiamente dicha, sí de similares

${ }^{7}$ Német, 2006: 59. Al parecer Marcel Nemes la había adquirido en 1912 de la subasta de la colección Weber de Hamburgo. Debió de estar colgada en el castillo de Tutzing, junto al resto de su colección, hasta 1918, en que la misma se dispersa.

8 Palencia Cerezo, 2001:107.

9 Véase Finaldi, 2016: 337-339, obra 141. 


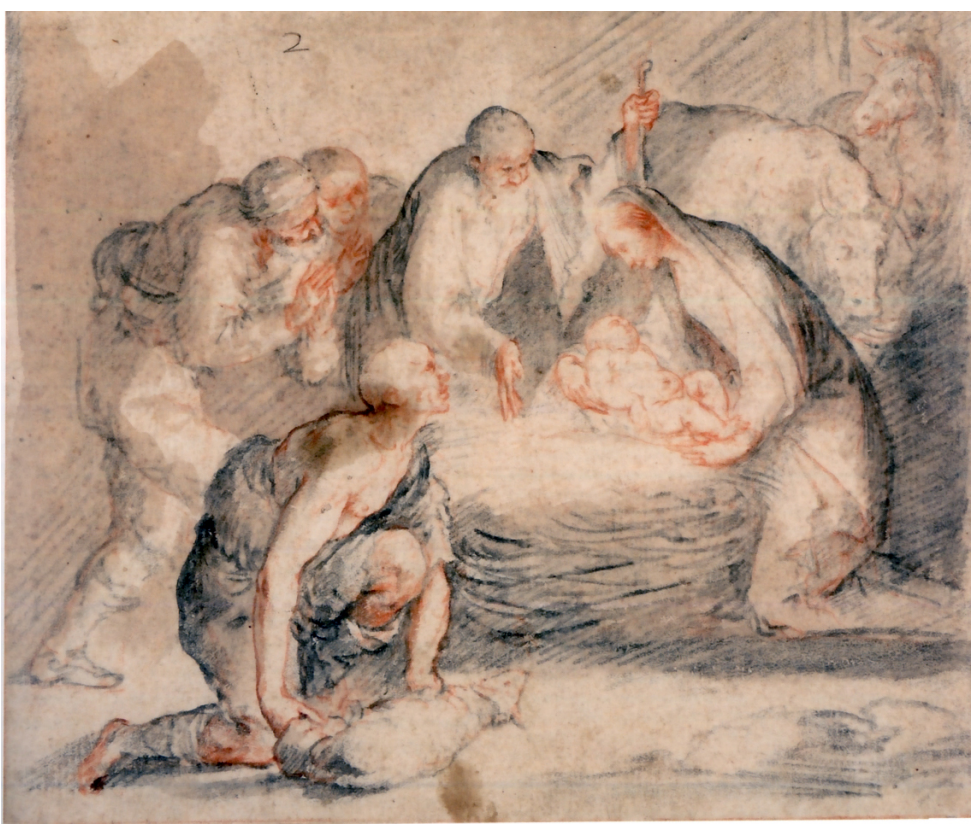

Fig. 3. José de Ribera. Adoración.

Museo de Liverpool

características a la de hacia 1645 que cuelga en las paredes del Museo de la Real Academia de San Fernando, hoy atribuida a su discípulo Giovanni Do (Antes de (1601- Hac.1656). Ambas serían copia de otra versión autógrafa del maestro, que en el siglo XIX perteneció a don Pedro Jiménez de Haro, y que ha sido estudiada recientemente por Gómez Frechina, considerando que podría ser la encargada a Ribera por el protonotario valenciano Cristóforo Papa en 1640, hoy en manos de la casa Colnaghi. Dicha composición tuvo bastante éxito en España, existiendo también otras copias conocidas, como la del monasterio sevillano de Santa Paula. ${ }^{10}$ (Fig.4)

En ella nos encontramos con una fórmula compositiva más elaborada y rica en personajes, sin duda más cercana al lienzo de Ribera de la misma temática existente en El Escorial, y que habría que relacionar con el dibujo del Kupperstich Kabinett de Berlin, fechado por Finaldi en 1650, pero también posiblemente de la década anterior ${ }^{11}$. Entre el anterior dibujo y éste, estaría el perteneciente al Metropolitan de Nueva York, considerado de la década de 1640, y más pobre de composición, que, no obstante, habría influido también decisivamente en diversas obras de sus discípulos, como la que conserva el Museo de Sao Paulo atribuida todavía a Bartolomé Passante.

\section{La influencia de Francisco de Zurbarán}

Hacia 1630 habría llegado también a Córdoba el lienzo que más controversia atributiva ha generado en relación a la pintura barroca cordobesa, y que nos habla ya de la segunda gran fluencia foránea en Córdoba: la del extremeño afincado en Sevilla Francisco de Zurbarán (1598-1664).

Se trata de la Adoración (165 x $205 \mathrm{~cm}$.) que también hoy se conserva en el Museo de Bellas Artes de Córdoba, y que se le vino adjudicando a José de Saravia. Esta no llegó al Museo como consecuencia de los procesos desamortizadores de 1835, sino en marzo de 1911, gracias a la intervención de Enrique Romero de Torres, encontrándose en el mismo en calidad de depósito del Instituto Provincial, es decir del antiguo Colegio de Nuestra Señora

10 Véase: Gómez Frechina, 2017, pp.10-11. Sobre esta última véase: Arteaga,1979. Quesada, 1997: 87.

11 Véase: Finaldi, 2016: 367-369, obra 155. 


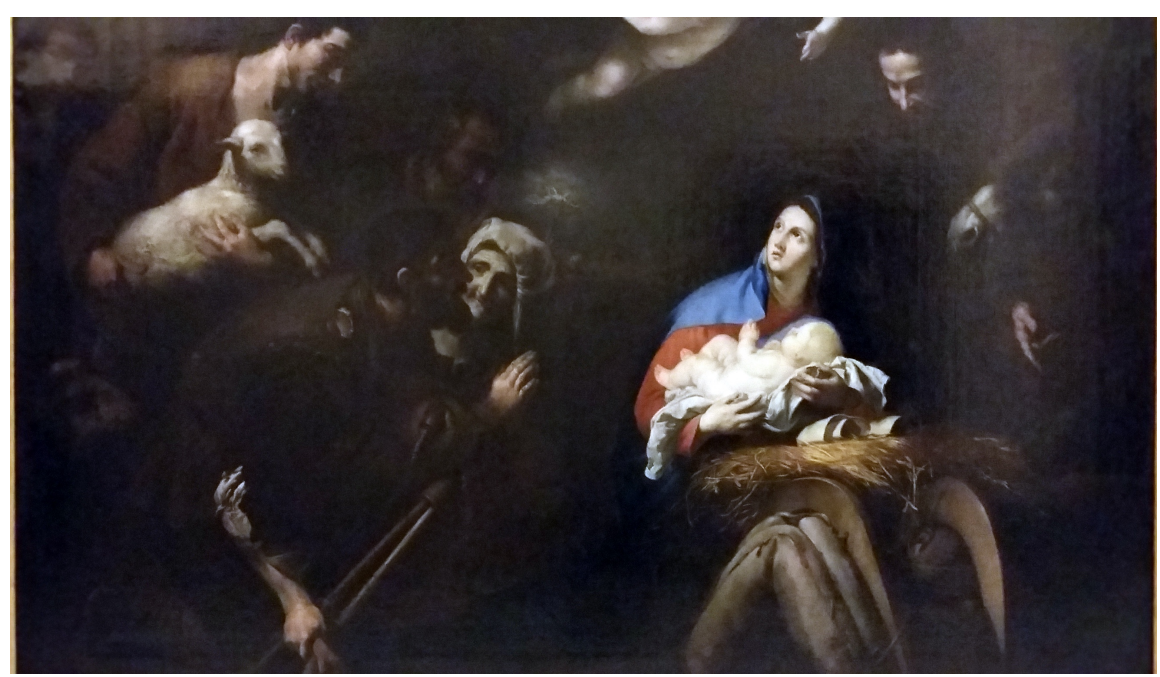

Fig. 4. Juan Do. Adoración. Madrid. Real Academia de San Fernando

de la Asunción, hoy Instituto de Enseñanza Superior Luis de Góngora. Fue precisamente Romero de Torres quien lo atribuyó, con dudas, a José de Sarabia, error que ha venido repitiéndose hasta la saciedad ${ }^{12}$. Sin embargo, como estudiamos en su momento, en la documentación existente en el archivo del museo sobre el proceso del depósito, algunas veces aparece claramente vinculada a Sarabia, mientras que, en otras, se utiliza este apellido seguido de interrogación, o bien utilizando el término "atribuido a". Ello nos indica que el propio Enrique Romero no estaba seguro respecto a la autoría de esta pieza, que no está firmada, sino solo fechada en $1630^{13}$. (Fig.5)

Por ejemplo, en 1957, Genevieve Moracchini, estudiando con detenimiento la Adoración de los pastores existente en la iglesia de San Andrés de Campana (Córcega), hermana de esta de Córdoba y no firmada ni fechada, puso el primer dedo en la llaga. Y aunque para su trabajo tomó como referencia solo la Adoración de Zurbarán, firmada y fechada en 1638, que se conserva en el Museo de Grenoble procedente de la Cartuja de Jerez y otra de que posee la National Gallery de Londres, no se atrevió a enjuiciarla de forma definitiva, pues solo la conoció por fotografía .

Tras ella terciaría en el debate Ortíz Juárez, que en 1960, expresó de manera rotunda la duda de que fuese de Sarabia por el simple hecho de que, como tal, allí figurase, insistiendo en que podría ser del maestro de Fuente de Cantos, aunque posiblemente no todo el cuadro fuese suyo, ahondando en la contradicción de quee el cuadro de Grenoble estuviese fechado en 1638, mientras el de Córdoba lo estaba 1630 . Un año después, salía a la luz el estudio que, a mi juicio, más ha influido en la defensa de la atribución a Sarabia, aunque ello haya sido en base a la aportación de un dato erróneo. Se trata del trabajo que Valverde Madrid dedicó al artista en 1963, donde, junto a una valiosísima aportación documental inédita para conocer su vida, escribió que estaba firmada y fechada, lo que ponía fuera de toda duda la autoría. Conocedor de los textos de Moracchini y Juárez, defendió allí también que tanto la de Córdoba como la de Campantá eran de Saravia, y que todas estas Adoraciones debían tener detrás un grabado desconocido. No pasaría mucho tiempo sin ser replicado, ya que con motivo de la exposición sobre el III Centenario de la muerte de Zurbarán, el conocido zurbaranista

\footnotetext{
12Véase, por ejemplo, Quesada, 1997:114.

13Palencia Cerezo, 2000; 2001.

14 Moracchini, 1957: 42.

${ }^{15}$ Ortiz Juárez, 1960.

16 Valverde Madrid, 1963:12.
} 


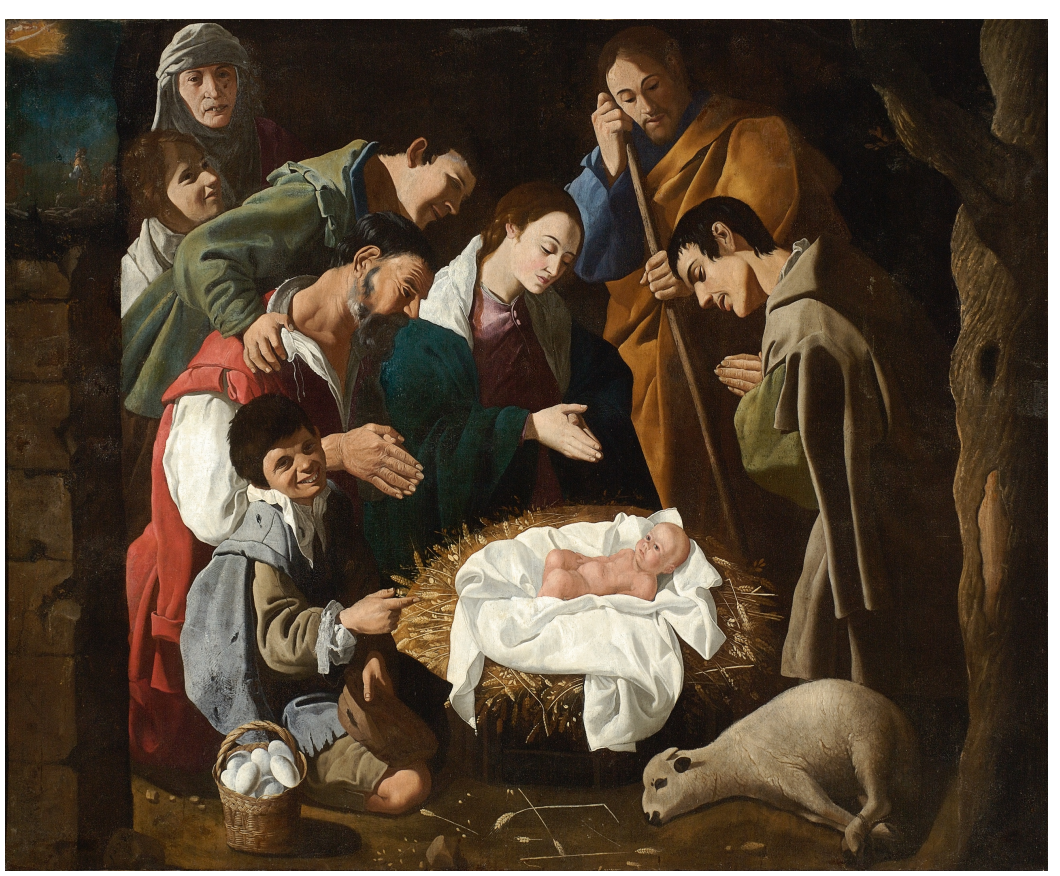

Fig. 5. Obrador de Zurbarán. Adoración. 1630. Museo de Bellas Artes de Córdoba.

gaditano Cesar Pemán, se haría eco de las posiciones de Valverde en los siguientes términos: "un estudioso cordobés, habitualmente concienzudo", afirma que la obra está firmada y fechada, lo que llama la atención, "...de modo que si la firma del de Córdoba es auténtica y la fecha está bien leída antecedería en ocho años al de Zurbarán (de Grenoble), hecho de lo más inverosímil. Si no hay error de lectura, que es lo probable, el hecho no admitiría otra explicación que el que ambas pinturas dependan de una fuente común, quizá un grabado, como ha dicho el estudioso que nos ocupa, pero lo cierto es que tal grabado no es conocido y su aprovechamiento por ${ }^{1}$ el supuesto discípulo años antes que por el maestro y en forma parecida es muy increíble" .

En cualquier caso, y a pesar de las razonables dudas de Romero de Torres primero, Ortiz Juárez después y Cesar Pemán más tarde, la atribución de la obra a Saravia se hizo paso hasta nuestros días, habiendo figurado como tal en diversas exposiciones y publicaciones de importancia. A título de ejemplo citaremos las exposiciones tituladas Antonio del Castillo y su época (Córdoba, 1986), Maestros barrocos andaluces (Zaragoza, 1988), Pintura mejïcana, pintura española, de los siglos XVI a XVIII (Méjico D.F., 1991) y De Velárquez a Murillo. El siglo de oro en Andalucía (Venecia, 1993). En todas ellas, historiadores como Mercedes Valverde, Enrique Valdivieso (1986), Fuensanta García, Ma Angeles Raya y Reyes López (1988) mantuvieron la atribución, que llegó a pasar incluso a las grandes historias del arte español. Así, a la Breve bistoria de la pintura española de Lafuente Ferrari (1953), al estudio sobre la Pintura española del siglo XVII publicado por Diego Angulo en Ars Hispaniae (1971), o al capítulo dedicado al El Arte del barroco, por Domingo Sánchez Mesa en la Historia del Arte de Andalucía (1991). Hay que hacer constar, sin embargo, que Alfonso Emilio Pérez Sánchez, entre las anotaciones que con tanta lógica formuló al catálogo de la primera exposición de Antonio del Castillo en Córdoba, - donde la misma figuró-, hizo notar que se había perdido la ocasión de aclarar definitivamente la cuestión, ya que por una parte se admitía que estaba firmada, y por otra la

17 Pemán, 1964. 


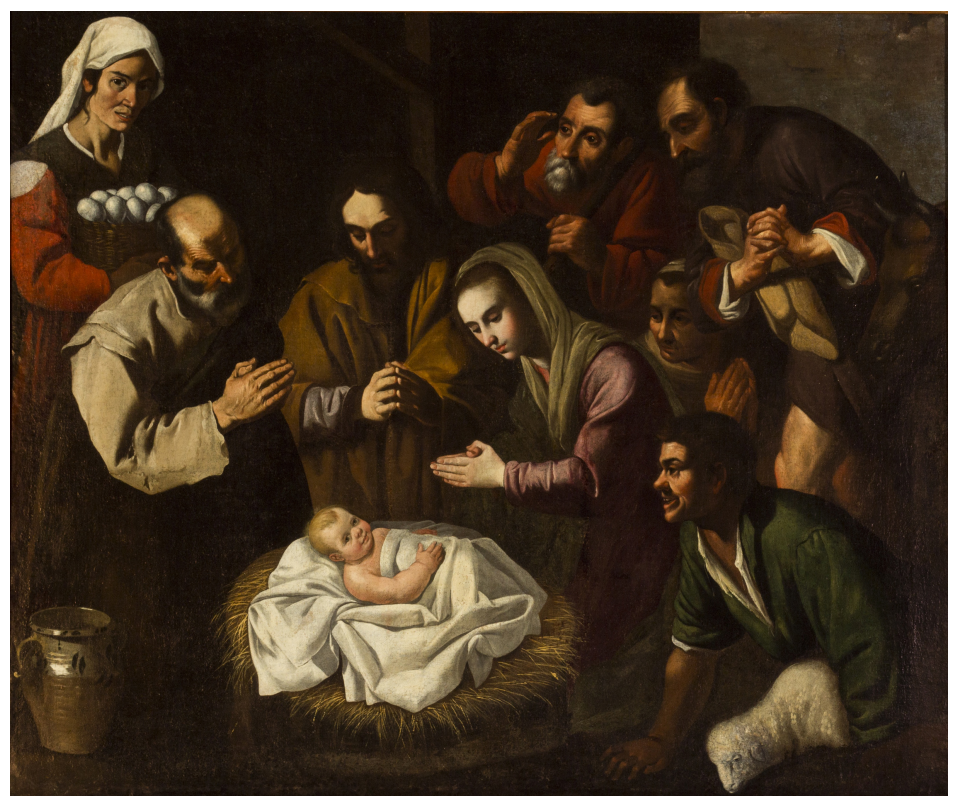

Fig. 6. Seguidor de Zurbarán. Adoración. Colección privada.

firma no aparecía por ninguna parte ${ }^{18}$. Parece que la estampa que más influyó a la hora de ejecutar la composición, fue la realizada por Boetius Bolswert en 1618, del cuadro original de Bloemaert que tanta influencia ejercería en la pintura barroca andaltza, incluso en los maestros de la segunda generación, como Murillo o Antonio del Castilllo .

Por lo demás, la obra es buena prueba de la existencia de un modelo, quizá por primera vez adoptado por Zurbarán y taller en el cuadro de Campana, y continuado luego pronto en el de Córdoba, finalizando con algunas variantes en la obra de la misma temática existente dentro de la que representa a San Nicolás de Bari en el coro alto de la iglesia del Monasterio de Nuestra Señora de Guadalupe (Cáceres), considerada de 1658, es decir, de la época de madurez de Zurbarán. A todas ellas podemos añadir otra de reciente aparición (103,50x123 cm.), como es la salida al mercado en la firma Balclis de Barcelona en octubre de 2018, como del círculo de Zurbarán, a nuestro juicio ya con muchos elementos del arte de Pablo Legot. (Fig.6)

A pesar de todos estos argumentos, ya expuestos por mi en 2000, en la tesis doctoral del profesor Valiñas se sigue considerando esta obra como de Saravia, y se supone de una calidad superior a la que sí es auténticamente suya: la de la Parroquia de San Francisco de Córdoba. Por lo demás, nada ha dicho sobre ella Odile Delenda en su reciente catálogo razonado de pinturas del maestro extremeño, sus seguidores y escuela ${ }^{20}$.

\section{El taller de los Ruiz de Saravia y su producción pastoril}

Como anunciamos anteriormente, uno de los talleres más significativos por los que transcurre el devenir de la pintura barroca cordobesa, será el de los Ruiz de Saravia, que es posible seguir mediante el estudio de otras tres Adoraciones, dos de las cuales se guardan igualmente en el Museo de Bellas Artes de Córdoba. La primera de ellas (167 x $204 \mathrm{~cm}$.), también procedente del convento de San Agustín, siempre estuvo atribuida en los inventarios

18 Véase Autores Varios, 1986: 138; Autores Varios, 1988: 51; Autores Varios, 1991: 78; Autores Varios, 1993: 114; Pérez Sánchez, 1987: 395-396 y Pérez Sánchez, 2010.

${ }^{19}$ Véase sobre este particular, Navarrete Prieto, 1998: 167-170.

20 Véase, Valinas López, 2005: 279 y Delenda, 2010. 


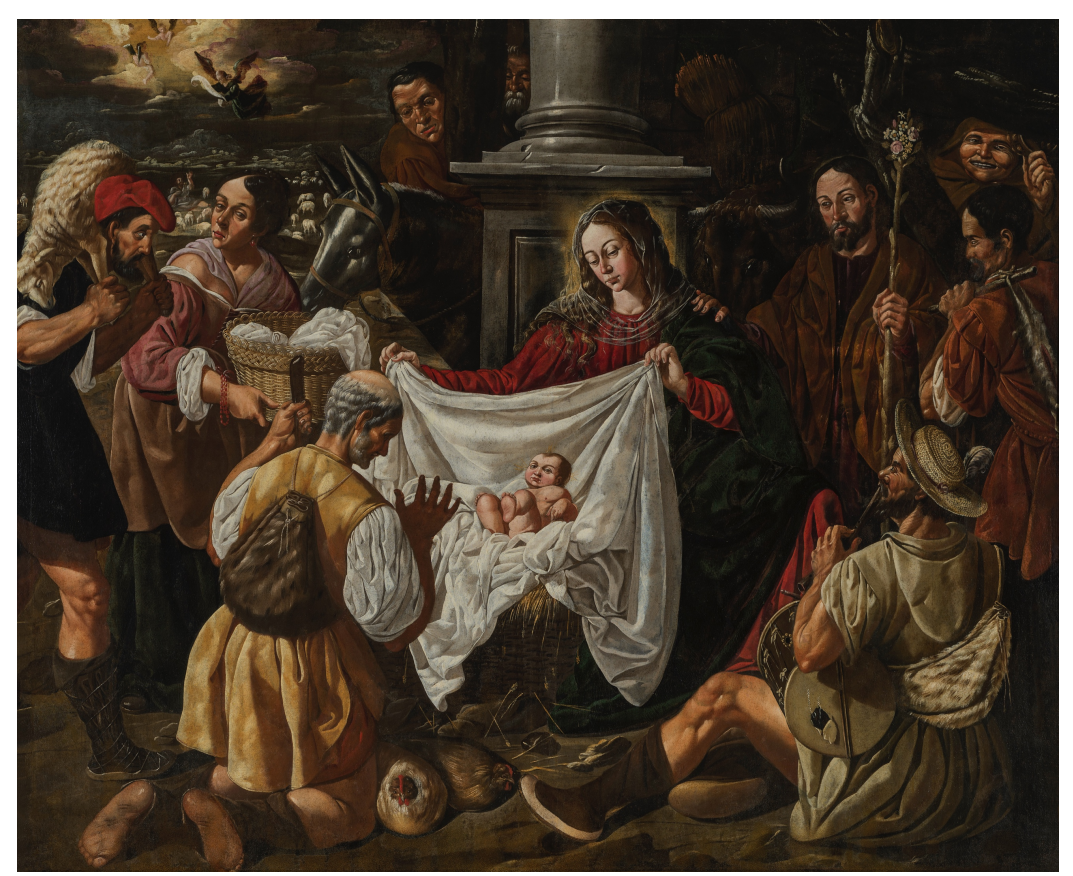

Fig. 7. Andrés Ruiz de Sarabia. Adoración. Museo de Bellas Artes de Córdoba.

de este Museo a Andrés Ruiz de Saravia, pintor al que se supone fundador de la dinastía. Dada la rotundidad de la atribución, que se viene arrastrando hasta nuestros días, y el estilo que presenta, ha hecho que su autoría nunca haya sido puesta en duda, a pesar de las lagunas existentes sobre la personalidad del artista, confundido con otro sevillano de idéntico nombre.

De esta suerte, uno sería el artista que figura en el testamento de Pablo de Céspedes como su ayudante, el cual permaneció acompañando a su maestro hasta en el lecho de muerte, ocurrido en 1608, por lo que se le ha de suponer nacido hacia 1580. Y otro, el artífice que debió nacer en Sevilla, donde junto a su hermano Melchor, habría regentado un taller bastante activo en la transición de centurias, aunque las obras que se le han podido documentar en la actualidad, han desaparecido. En cualquier caso, se piensa que debió de ser bastante influyente, ya que fue incluido por Palomino entre sus biografiados, habiéndose desmentido en la actualidad algunas cuestiones apuntadas por el bujalanceño, como su supuesta marcha a las Indias en 1616, demostrándose que hacia 1625 habría contratado en Sevilla el dorado y estofado unos lienzos con historias de Santa Catalina para el retablo mayor de la parroquia de ésta advocación, estando avecindado en 1634 en la collación de San Marcos . Dicha demostración se fundamenta en el hecho de que uno de los lienzos de este retablo, - que se contrata entre 1628 y no se dora hasta 1669 -, concretamente el que representa La visión de los animales impuros por San Pedro, está firmado con un monograma que se corresponde con las iniciales del nombre y apellidos del artista ${ }^{22}$.

Aunque de forma más seca y amanerada, el estilo y la composición de esta Adoración -que hay que seguir creyendo que sea del Andrés Ruiz cordobés-, concuerda con las de las distintas versiones de la temática realizadas en la Sevilla del momento, pudiendo compararse con la de

${ }^{21}$ Cuéllar Contreras, 1982.

22Véase Delenda, 2010: 227-229. Salvo eso, nada más. En todo caso, la hipótesis con la que trabajamos es la de que en su obrador debió formarse, en un primer momento, su hijo José, que nace en Sevilla en 1608, y se establece definitivamente en Córdoba en fecha tan significativa como 1629, donde hasta su muerte, ocurrida cuarenta años después, habría mantenido un nuevo taller que heredaría su hijo Andrés, entrando en competencia con los pintores locales más significativos del momento. 


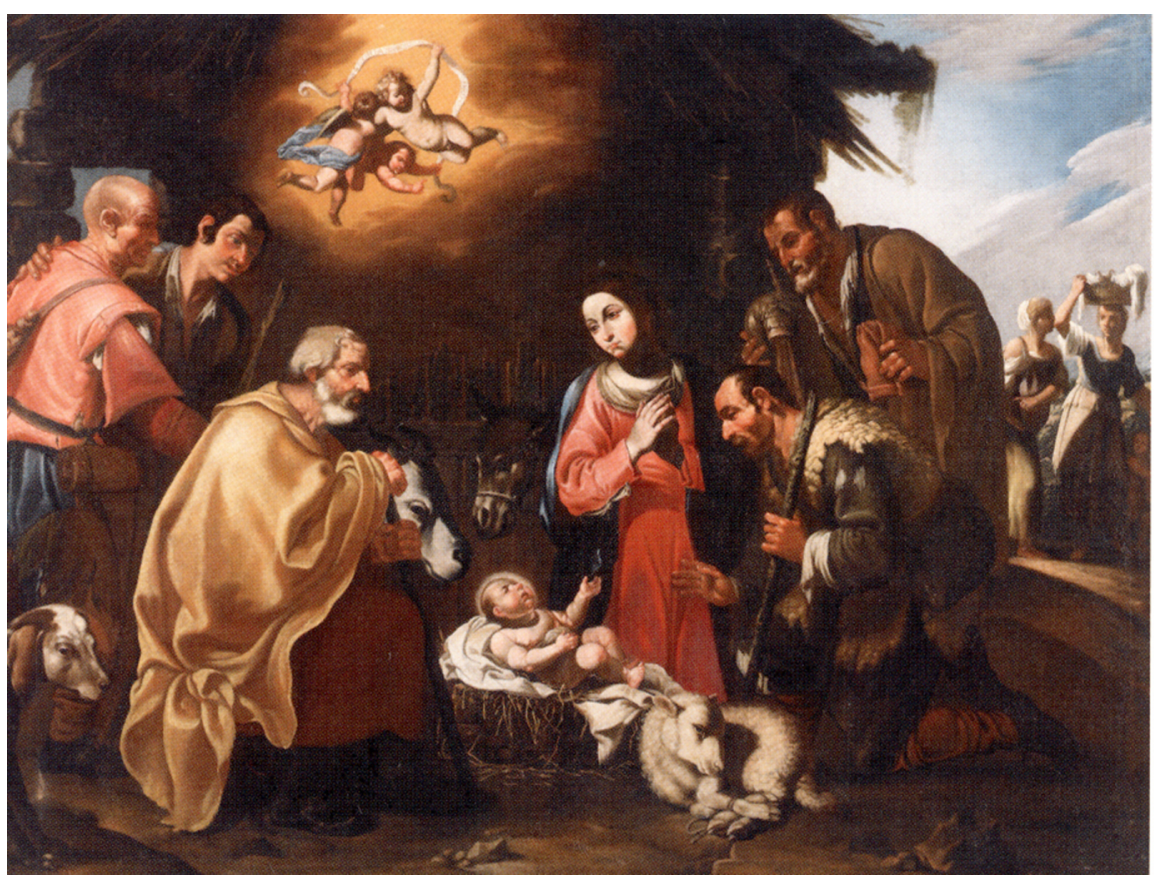

Fig. 8. Anónimo Cordobés. Adoración. Colección particular

Juan de las Roelas, de hacia 1604-06, destinada al retablo mayor de la iglesia jesuita de la Anunciación; o con la de Juan del Castillo, de hacia 1615, que guarda el Museo de Bellas Artes de Sevilla como proveniente del retablo de la parroquia de Monte Sión ${ }^{23}$.

En todas ellas, María es presentada destapando al Niño, para mostrárselo mejor a un pastor que se le arrodilla enfrente, trasponiendo el modelo italiano renacentista de la Virgen del velo procedente de Rafael, que tan difundido fue mediante diversos grabados durante el siglo XVI, pasando también a la estampas de pastores; como vendría a demostrar el grabado anónimo aparecido en la edición del Thesaurum Sacrum historiarum (1585) de Gerad de Jode, que condensa igualmente las tres escenas posibles: Anunciación, Natividad y Adoración. Como es fácil suponer, Andrés Ruiz habría tomado de esta estampa la columna que centra la composición, el ángel que anuncia por la zona superior izquierda en paisaje abierto, la Virgen abriendo la sábana con las dos manos y el pastor itinerante que aparece en primer plano por la izquierda; que él convertirá en "Buen Pastor", colocándole un gorro rojo y situándolo junto a una mujer que porta una cesta con pañales o sábanas. La obra debió ser realizada hacia 1625-30, y más allá de otro tipo de consideraciones hay que resaltar su importancia para el desarrollo de la pintura cordobesa, porque los personajes anteriormente descritos, más el pastor arrodillado situado frente al Niño con su característico morral, serían a partir de entonces temas recurrentes o invariantes, perdurando hasta la segunda mitad del siglo XVIII, como se podrá comprobar con lo que sigue. En cualquier caso, en ella estarían presentes dos constantes influencias que se van a repetir en la pintura barroca cordobesa: por un lado, la de Pedro Orrente, y por otro, la de la estampa del cuadro de Ambraham Bloemaert existente en el Museo del Louvre, grabado por Shelte Bolswert en 1618. (Fig.7)

Muy cercana a la composición y también al autor del cuadro anterior, se muestra otra Adoración (140 x $112 \mathrm{~cm}$.), en este caso de colección particular, que fue recientemente sacada al mercado por la casa de subastas Sotheby's como de un anónimo cordobés. La influencia parece clara y, más allá de la belleza o bondad de la obra, su artífice parece haber visualizado el cuadro de la National Gallery que fue del Conde del Aguila, y que nosotros creemos

23 Palencia Cerezo, 2016: 97. 
situado en la órbita de Phillipe de Champaigne. La influencia es clara, especialmente por las mujeres que se acercan al portal desde el fondo, por la parte derecha de la composición. La primera de ellas porta un cesto de pañales limpios en la cabeza, al igual que sucede en el cuadro de Londres. Por lo demás, no debió de haber sido realizada más allá de 1640, presentando también una singular influencia del grabado de Durero estampado por Raimondi, tanto en la composición general del cobertizo, como especialmente en el pastor que aparee en segundo plano por la derecha, gorra en mano, tocando la gaita. (Fig.8)

En todo caso, el cuadro cordobés que más se ha acercado al estilo de Zurbarán es la Adoración de los pastores de José de Saravia (Sevilla,1608 - Córdoba, 1669) que pertenece a la actual parroquia de San Francisco y San Eulogio de la Axerquía. Mide 216 x 141 centímetros, y siempre ha sido publicada como suya ${ }^{24}$. Como expusimos en 2001, debió ser financiada por los señores Fernández del Castril y de las Casas en 1652, đẹe habían conseguido para su enterramiento el patronazgo del altar que la obra preside. Según Valiñas, su esquema compositivo debe mucho a la experiencia toledana de Pedro Orrente, presentando una estrecha relación con el cuadro de igual tema del desaparecido retablo de Villarejo de Salvanés, del que existe una réplica en el Museo de Santa Cruz de Toledo ${ }^{26}$.

Fue Palomino quien, en su biografía sobre este artista, informó de su gusto por la utilización de estampas, en especial de Sadeler, a pesar de lo cual sabía plantear sus creaciones de manera muy inteligente. Ello puede apreciarse también en la obra, donde combinó con maestría su inspiración en alguna estampa con remembranza de Durero, -como pone de manifiesto la manera en que María sujeta la sábana para mostrar al Niño con una sola mano, mientras mantiene la otra en el pecho-, y la composición realizada por Abraham Bloemaert para la iglesia de San Jacobo de la Haya, grabada muy prontamente, y de la que copia el angelito del rompimiento de gloria que porta la filacteria, inspirando también elementos como el cordero, el pastorcillo situado detrás del buey, y la cesta que lleva la pastora entre los brazos, ubicada por Bloemaert en primer plano, en el suelo.

Por lo demás, resulta también evidente la relación con el propio obrador familiar, de la Adoración de los pastores (112,5 x 168,5 cm.) atribuida a Andrés Ruiz de Sarabia Navarrete (1653-1738) por Enrique Romero de Torres, que también conserva el Museo de Bellas Artes de Córdoba depositada por la parroquia de San Francisco y San Eulogio de la Axerquía en 1926. Como igualmente expresamos en su momento, en la iconografía de este lienzo se suman tres fuentes de inspiración distintas. Por la zona izquierda, el pastor con gorro y cordero a los hombros y la pastora que porta una cesta con frutas y verduras, son de tradición orrentiana y están claramente inspirados en el cuadro de su supuesto abuelo. Por la parte central derecha, Virgen, Niño, pastor arrodillado con las manos juntas, cabeza de buey y perro que permanece echado mirando hacia el espectador son copias casi literales del grabado realizado por Bolswert de la composición de Abraham Bloemaert que se conserva en el Louvre. Por último, los ángeles que figuran en la parte superior derecha de la composición habrían sido interpretados del grabado de Cornelio Cort sobre composición de Federico Zuccaro. (Fig.9)

\section{Las Adoraciones de Antonio del Castillo: antecesores y seguidores}

Frente a la escasez de obras con que hemos contado en relación a los episodios anteriormente estudiados, respecto a Antonio del Castillo Saavedra (1616-1668) el número de piezas aumenta considerablemente, pues son nada menos que una docena de lienzos los que se vienen adjudicando a su pincel. Sin embargo, estamos convencidos de que no todas son suyas, por lo que trataremos de poner un poco de orden y concierto en cuanto a este parámetro, estudiándolas de manera cronológica.

\footnotetext{
24 Por ejemplo, Quesada, 1997:112-117. García de la Torre / Navarrete Prieto, 2016:116.

${ }^{25}$ Ramírez de Arellano, (1874): 293.

26Valiñas López, 2005: 283.
} 


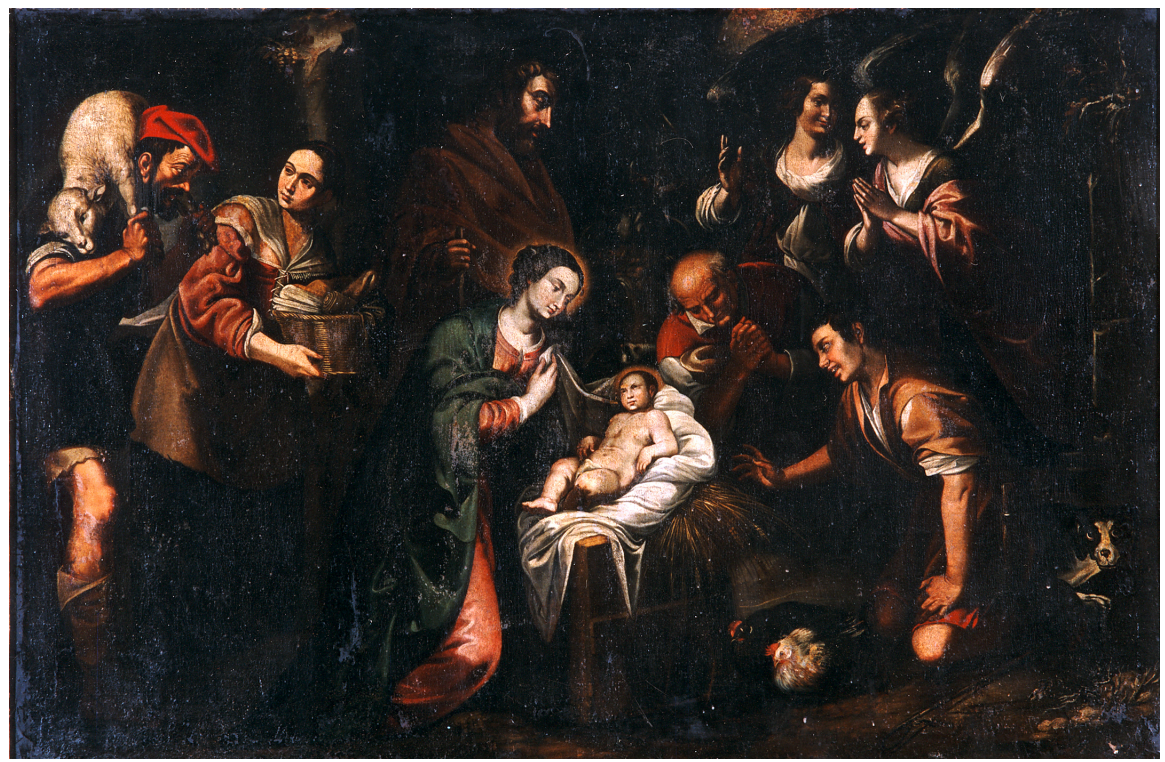

Fig. 9. Andrés Ruiz Sarabia el joven. Adoración. Museo de Bellas Artes de Córdoba.

La primera de estas obras es la que se conserva en el pasillo anterior al salón de plenos del Ayuntamiento de Córdoba (155 x $115 \mathrm{~cm}$.), formando pareja con una Anunciación $\mathrm{Ha}$ sido considerada desde siempre obra de Castillo, aunque para nosotros, por la gran cantidad de rasgos arcaicos que presenta, es sin duda, de su padre. De esta manera, contrariamente a lo que se viene afirmando, consideramos al propio Agustín del Castillo, fundador de un taller que, protegido y trabajado al lado de Juan Luis Zambrano, llegaría a su momento culminante a partir de 1640, siendo prolongado a través de la obra de diversos discípulos y colaboradores del propio Antonio, en especial por Pedro Antonio Rodríguez y Manuel Francisco Arias, a los que Palomino consideró sus principales discípulos.

Como vio Moreno Cuadro en 1994, en ella se vuelve decisiva la influencia del grabado de Bloemaert, lo que viene a poner de manifiesto cómo Castillo también heredó de su padre esa especial preocupación naturalista procedente del mundo manierista flamenco. Por lo demás, a pesar de que no ha sido restaurada modernamente, presentará evidentes ecos basanescos, pareciendo desarrollarse de noche, sin que se puedan apreciar con a suficiente claridad sus motivos arquitectónicos.

Una versión más completa que ésta, que introduce zona de gloria y un niño pastor de frente por la parte izquierda que sonríe tocando el tamboril, se conserva en una colección particular de Madrid. Esta segunda fue publicada por Navarrete Prieto como original de Castillo, aunque, a nuestro juicio, por la impronta de sus tipos, se trata de una obra de Juan Luis Zambrano ${ }^{27}$. Por el momento no hemos podido localizarla, por lo que la atribución propuesta tiene carácter provisional, resultando evidente que, tanto en una como en otra, hay elementos como para poder ver su relación con el grabado de Boecio Bolswert de 1618 copiando a Bloemaert, Lo que pone de manifiesto nuevamente la presencia de esta influyente estampa en Andalucía, en la década de 1620, es decir, muy poco después de su salida al mercado. (Fig. 10)

En todo caso, para el estudio de las Adoraciones de Antonio resulta necesario partir del dibujo que forma parte del Álbum Alcubierre, firmado por el artista en 1644, puesto que la mayoría de ellas van a tomar algún detalle del mismo ${ }^{28}$. Dibujo que tiene también presente la

${ }^{27}$ Navarrete Prieto, 1998: 272.

28 Véase su estudio en Navarrete Prieto, 2006: 44. Navarrete Prieto / Pérez Sánchez, 2009. 
Fig. 10. Juan Luis Zambrano. Aquí atribuido. Adoración. Madrid. Colección privada.

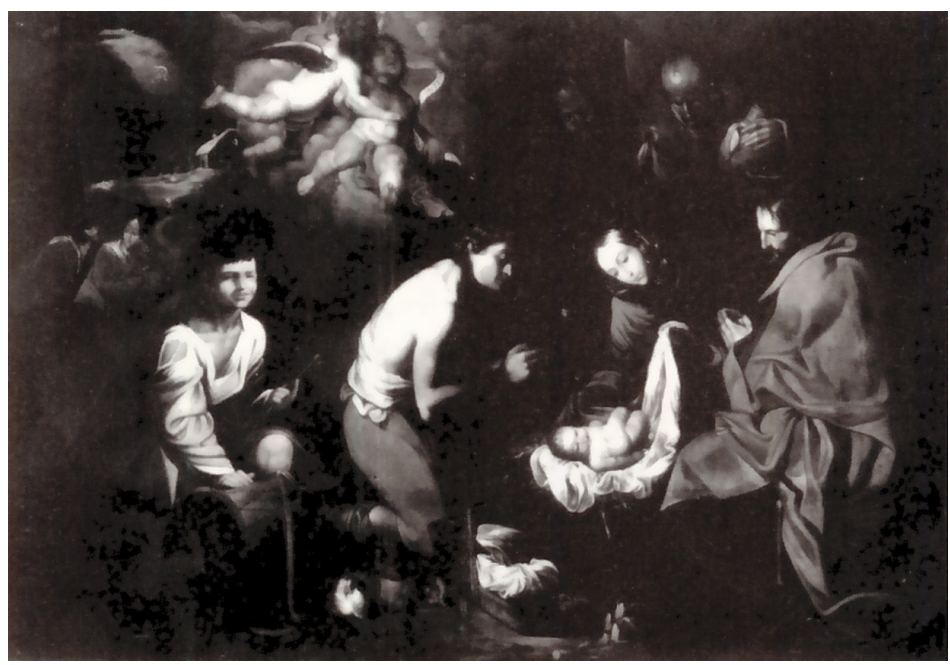

obra de su padre, especialmente en la disposición de María con el Niño, y en el pastor arrodillado que aparece por la izquierda con el torso desnudo, que puede verse en otras versiones conocidas del pintor, como la de la colección Masaveu, o la que fue de la antigua colección Ibarra, aunque ésta se inspire fundamentalmente en el grabado realizado por Jan Müller en 1606 a partir de una famosa composición de Bartolomé Spranger.

De esta manera, puede decirse que con el lienzo que perteneció al Infante don Sebastián Gabriel de Borbón (204 x 165 cm), actualmente conservado en el Museo de Bellas Artes de Asturias como parte de la colección Masaveu, - antes en la de don Enrique Pelta-, firmado y fechado por Antonio del Castillo en 1651, no solo asistimos a la generalización de los ingredientes típicos de las Adoraciones de este maestro, sino también de esa pintura barroca cordobesa que podíamos considerar de segunda generación.

Con parecidos ingredientes, el concepto compositivo de Castillo evolucionará hacia una mayor simplicidad en la obra que pertenece al Museo del Prado (216 x $163 \mathrm{~cm}$.), actualmente depositada en el Museo de Málaga; que para algunos fue realizada hacia $1649-51^{29}$, mientras que otros la dan como de hacia $1655^{30}$. De la misma se ha valorado su osadía en colocar la cunita del Niño prácticamente sobre el lomo del buey; mientras que la existencia de dos pastores adultos junto a un niño tamborilero, y especialmente la de la vieja partera que acude a la celebración, van a ser los aditivos más evidentes y populares de la composición.

Como gran obra maestra hemos de considerar también la Adoración que guarda en Nueva York la Hispanic Society of America (112x 144,5 cm.). Perteneciente a una colección privada de Alemania, fue adquirida por dicha institución en 1963. Con los mismos ingredientes anteriores, el pintor rebaja aquí su formato para hacerse más empirista, es decir más "narrativo", De ella existe una copia en la parroquia de San José del Campo de la Verdad Córdoba $^{32}$.

Mayor influencia del taller del propio maestro observamos en el cuadro $(140 \times 105 \mathrm{~cm}$.) hoy propiedad de Caylus Anticuarios, que procede de una colección privada de Granada. En la actualidad ha sido estudiada fundamentalmente por Benito Navarrete, que no ha dudado de su adscripción al artista ${ }^{33}$. No obstante, para nosotros es de menor calidad y habría que relacionarla con la actividad de Pedro Antonio Rodríguez (Hac. 1615 - 1675), su supuesto

\footnotetext{
${ }^{29}$ Nancarrow / Navarrete Prieto, 2004: 246.

30 Quesada, 1997: 114-116.

${ }^{31}$ Nancarrow / Navarrete Prieto, 2004: 248. Para sus probables dibujos preparatorios véase García de la Torre / Navarrete Prieto, 2016:111 y 120.

32 Véase, por ejemplo, Autores Varios, 1986: 62. Valiñas López vio en ella influencia del barroco napolitano, sin especificar a qué autor, o qué obra de ese ámbito de la pintura italiana estaría referida, añadiendo también su parentesco con la Adoración de Murillo conservada en el Museo del Prado, obra contemporánea en la que serían idénticas las actitudes de la Virgen y el Niño. Valiñas López, 2005: 286-287.

33 Nancarrow / Navarrete Prieto, 2004: 250.
} 


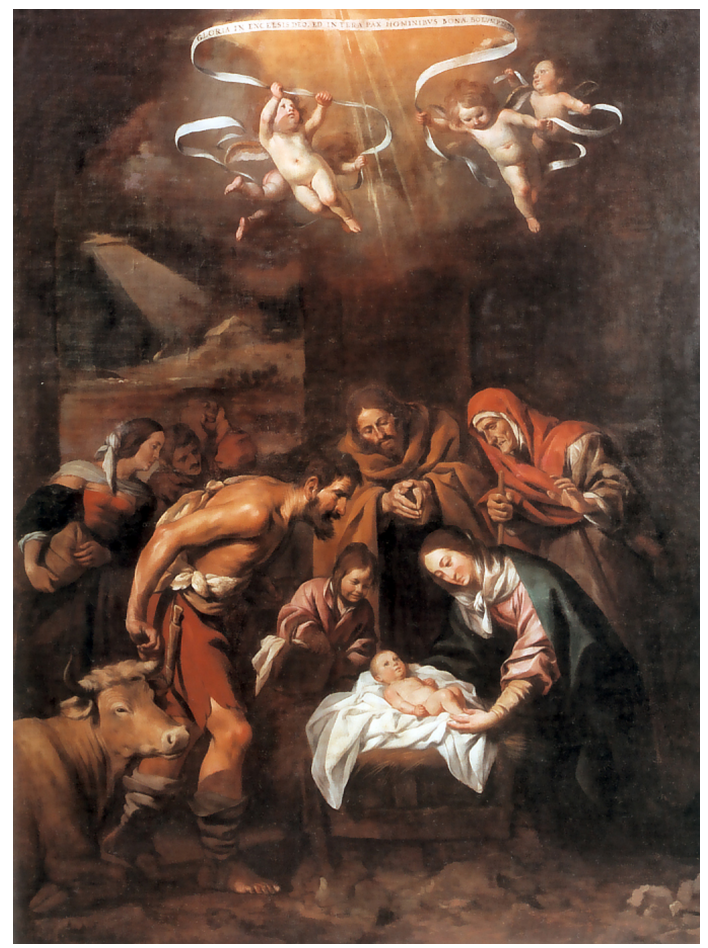

Fig. 11. Antonio del Castillo y taller. Adoración. Madrid. Caylus anticuarios.

discípulo, siendo de destacar en ella su acusada simetría compositiva, la presencia de la niña pastora que porta la cesta de pañales y se dirige hacia el espectador mirando fijamente a Jesús, más el pastor colosal que, por la izquierda, sostiene los cuernos el buey, como se da en la pintura del Museo de Bellas Artes de Asturias. (Fig.11)

Mejor factura presenta la Adoración (58 x 59,5 cm.) hoy perteneciente a Cajasur y depositada en el Palacio de Viana de Córdoba. De formato casi cuadrado, hace pareja con una Epifanía en la que se llegó a inspirar Palomino para hacer en Córdoba sus primeras y novedosas representaciones de ambos asuntos y se le viene suponiendo una fecha de realización de hacia $1660^{34}$. En ella debemos de destacar de nuevo al niño, que señala con el dedo a una dádiva de gallinas, así como la presencia en primer plano del buey, emblemático detalle del empirismo naturalista que interesó siempre al artista. Dicho buey figura de manera parecida en un pequeño lienzo $(34,5 \times 30 \mathrm{~cm}$.) que se encuentra en una colección particular de Ecija (Sevilla), debida al taller o a algún colaborador cercano del artista, que ha situado por delante del mismo a un pastor, presentado, por la derecha, a María sujetando al Niño, para mostrarlo de forma parecida a como lo hace en el cuadro que a continuación comentamos.

Se trata de la obra que perteneció a la colección Ibarra de Sevilla $(126$ x 103,5 cm.) y fue vendida en la subasta extraordinaria de 8 de junio de 2000 por la casa de subastas La Habana de Madrid ${ }^{35}$. A raíz de ello, Navarrete realizó un elocuente estudio, donde puso de manifiesto su mayor vinculación estilística y semejanzas de factura con la obra de Cajasur, lo que nos daría una cronología similar, entroncada con los últimos años de la vida de Castillo. Es, tal vez, su obra más interesante, donde introducirá todos los recursos compositivos a su alcance, potenciando la luz que viene del cielo para iluminar en diagonal al Niño, procedimiento que no había realizado hasta el momento de manera tan rotunda.

Por último, en una colección particular cordobesa $(205$ x $160 \mathrm{~cm}$.) existe otra obra que normalmente se ha venido adjudicando al maestro ${ }^{36}$, aunque para nosotros sería también de taller, ya que si por un lado no presenta calidades cercanas a las del maestro, por otro es

\footnotetext{
34 Nancarrow / Navarrete Prieto, 2004: 254.

35 Nancarrow / Navarrete Prieto, 2004: 252.

36 Autores Varios, 1986: 78.
} 


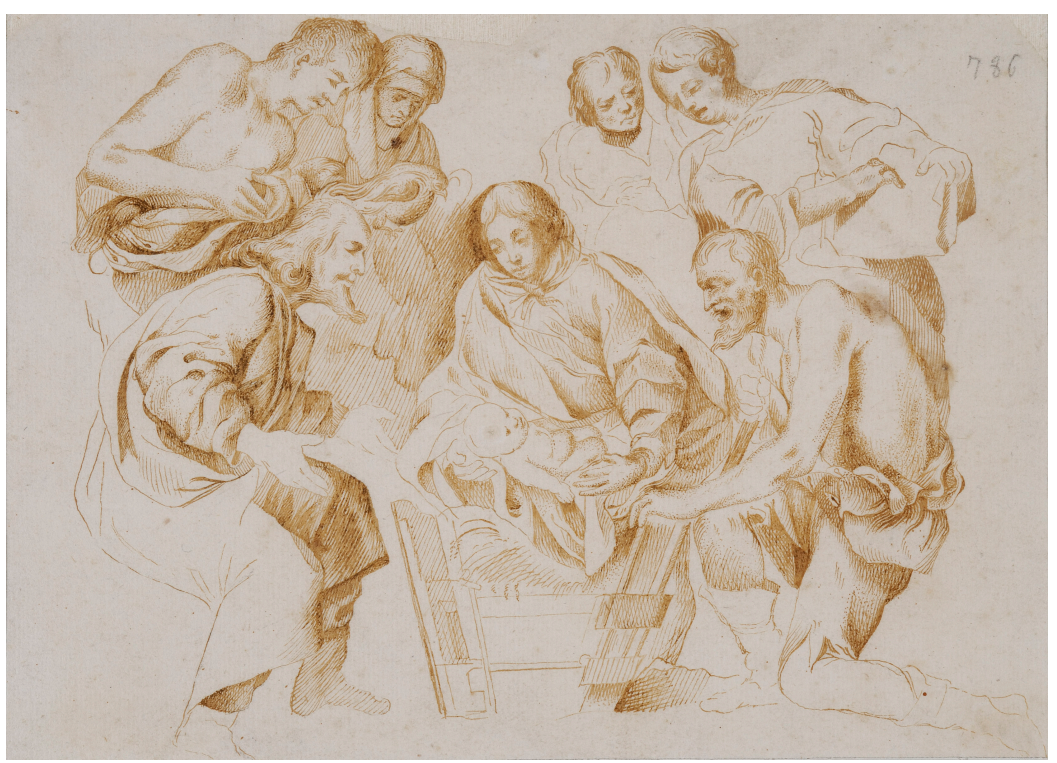

Fig. 12. Manuel Francisco Arias. Aquí atribuido. Adoración. Museo de Bellas Artes de Córdoba

posible apreciar en ella, con mayor énfasis, si cabe, la pincelada y los tipos de Pedro Antonio. En realidad, se trata de un remedo de la firmada por Castillo en 1651 del Museo de Bellas Artes de Asturias. En ella se abunda en la geometría y aunque el paisaje de fondo está tratado correctamente, falta el típico rompimiento de gloria con ángeles, y esa filacteria que suele dotar de gracia y majestuosidad a sus obras de gran tamaño.

Como de sus seguidores más tardíos hemos de considerar la Adoración perteneciente a una colección particular de Madrid (70,5 x $125 \mathrm{~cm}$.) que fue subastada en la capital de España por Fernando Durán, el día 5 de julio de 2013, con la autoría de Castillo y taller. Es una obra cuyo autor se ha servido en la parte inferior izquierda de algunas de las composiciones de Castillo analizadas, utilizando para la parte derecha el famoso grabado de Lucas Vosterman sobre composición de Rubens estampado en 1620.

Entre las obras realizadas por seguidores tardíos de Castillo, por el momento todavía anónimos, se encuentra también el gran lienzo $(213$ x $144 \mathrm{~cm})$ que guarda el Museo de Bellas Artes de Córdoba depositado por la Diputación desde 1917, que procede del desaparecido hospital del Cristo de la Misericordia, un establecimiento benéfico el barrio de Santa Marina tutelado por la misma a raíz de su supresión ${ }^{37}$. Más allá de que su autor pudiera haber sido Manuel Francisco de Arias Contreras, lo que es probable, su importancia deviene del hecho de presentar dos inscripciones. Una en el angulo inferior izquierdo que dice: "Ludovicus Gomez. $\mathrm{Bra}^{\prime \prime}$. Fdez: Cor ${ }^{a v}$. Figueroa"; y otra en el ángulo inferior derecho que reza: "Iuan de Valdes. Pinto Anno Domini 1684". Sobre la segunda existe consenso en que se trata de una firma apócrifa que intenta hacer de ella un original de Valdés Leal, siendo verosímil que hubiese sido realizada en 1684. Más importante, sin embargo, resulta la primera, para poder entenderla en relación con don Luis Gómez de Córdoba y Figueroa, Marqués de Villaseca. De él sabemos que moró en las casas hoy conocidas como Palacio de Viana - en su tiempo de las Rejas de Don Gome-, y que su familia poseía el patronato de la capilla mayor del Convento de Santa Isabel de los Ángeles, por lo que, desde 1585, venían costeando su fábrica, realizada sobre la de la antigua ermita de la Visitación 38. Al decir de Palomino, don Luis fue muy amigo de la

37 Sobre este Hospital se sabe que en 1640, un devoto llamado Gregorio Ponce, compró a los Padres de Gracia un solar cerca de la Puerta Excusada, en el barrio de Santa Marina, y labró una ermita a un Crucifijo de su devoción, al que daba el título de la Misericordia, alcanzando su mejor momento hacia 1690.

38 Véase sobre estas obras Luque Carrillo, 2016. 
Fig. 13. Sebastián Martínez. Córdoba. Adoración. Convento del Corpus Christi.

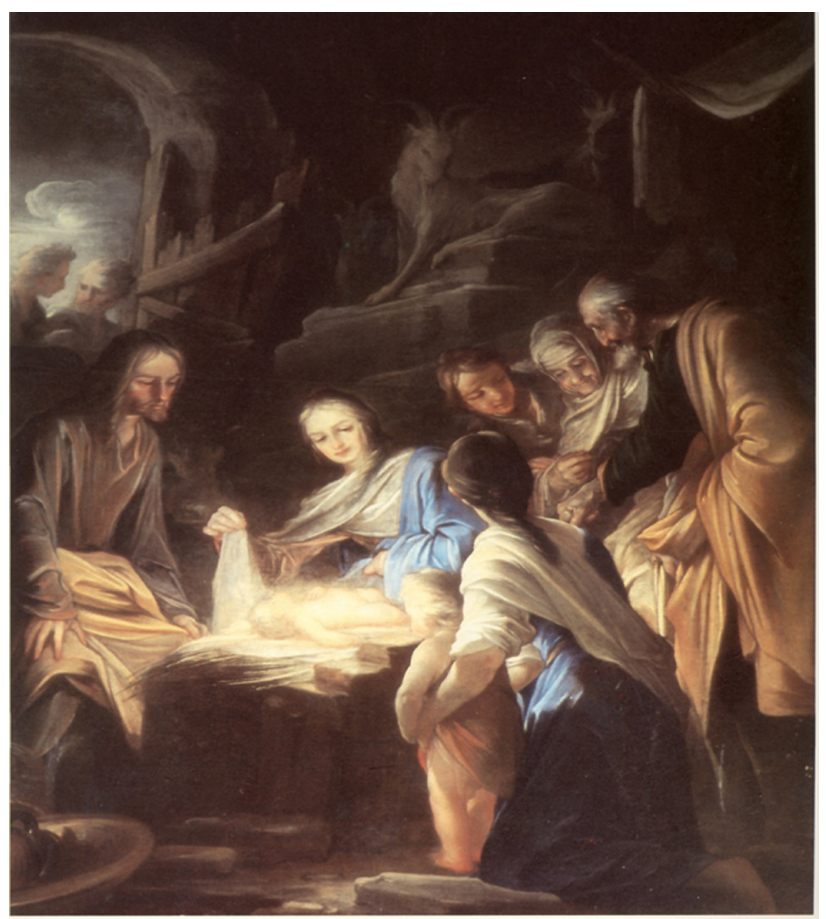

utilización de la simetría en las composiciones de los artistas a los que encargaba obras, que por lo general eran los más importantes del momento, a los que exigía estuviesen así compuestas, como se puso de manifiesto en las de varios importantes artistas que han llegado a nuestro tiempo. Como en esta Adoración, cuya inscripción delata haber sido encargada para que, por su gran formato, campeara en algún lugar destacado de este desaparecido establecimiento hospitalario, sobre el que los Villaseca también tenían patronazgo. Por lo demás, relacionado con este cuadro, también se conserva en el Bellas Artes de Córdoba, un dibujo que es, o bien trabajo compositivo preparatorio para el mismo, o bien copia de su motivo central por un posterior artista. (Fig.12)

\section{LA NOVEDOSA APORTACIÓN ICONOGRÁFICA DE SEBASTIÁN MARTÍNEZ}

Existe también en Córdoba una Adoración (140 x $138 \mathrm{~cm}$ ) de Sebastián Martínez Domedel (1615-1667), gran pintor de Jaén que mantuvo una estrecha relación con la ciudad ${ }^{39}$, realizada con destino al retablo mayor del antiguo convento de monjas dominicas del Corpus Crhisti. Tras la venta y conversión de este antiguo espacio conventual femenino en Fundación Antonio Gala para jóvenes creadores, se ubica actualmente en la nueva casa levantada por la orden en el extrarradio urbano. No se conoce su fecha de realización exacta, aunque se da por buena la de comienzos de la década de 1660, coincidiendo con el obispado de Alarcón y Covarrubias (1657-1675). Elogiada desde antiguo por Palomino y Ponz, que la titularon Nacimiento de Nuestro Señor, ha sido recientemente estudiada por los profesores Pérez Lozano y Galera Andreu, siendo este segundo el que ha realizado la lectura más novedosa de la misma, proponiendo incluso el cambio de su título actual por el antiguo. Las razones para ello estarían en que el Niño ilumina toda la escena, que se desarrolla en el interior de una profunda cueva que solo deja ver una difusa luz natural que entra por la zona superior izquierda. Además, en vez de una mula y un buey, Martínez solo plantó una pareja de cabras sobre una meseta pétrea plana situada por encima del cuerpo de María, cuyo macho cabrío presenta un estado inquietante, siendo su antecedente remoto el cuadro pintado por el Giotto en la capilla Scrovegni de Padua, donde también aparece este animal. (Fig.13)

39 Véase sobre este particular Palencia Cerezo, 2017: 96-97. 


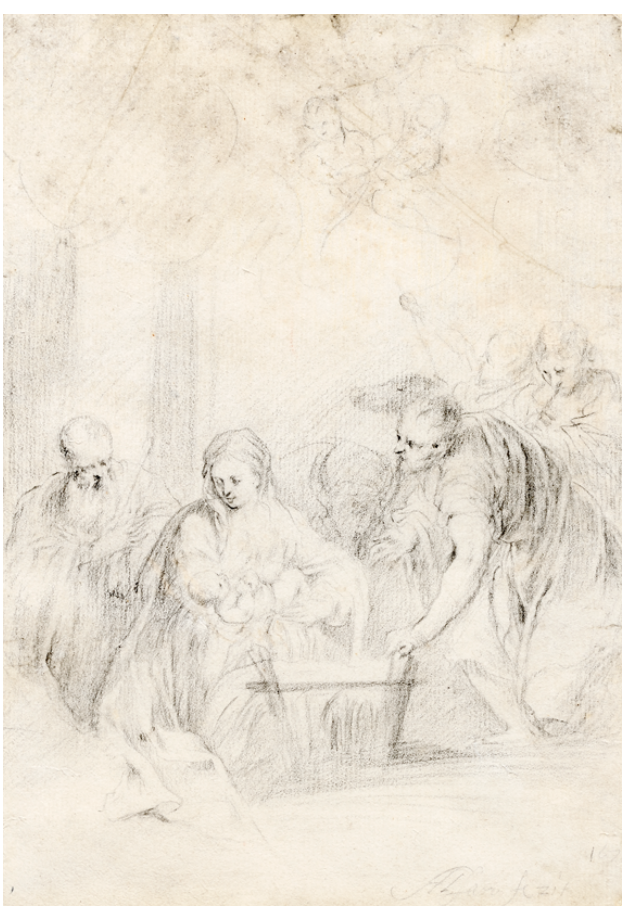

Fig. 14. Juan de Alfaro y Gámez. Adoración. Museo de Bellas Artes de Córdoba

Además, los personajes que figuran en escena no serían tales pastores, pues los dos ancianos que asisten gozosos podrían identificarse con los padres de la Virgen, San Joaquín y Santa Ana, abuelos de Cristo. Y la mujer de espaldas arrodillada, que sujeta al Niño, sería Santa Isabel, acompañada de San Juanito. Además: "Las dos cabezas dialogantes a la entrada de la cueva nos remiten a los evangelios apócrifos, cuando la partera Zaquel da cuenta del milagroso acontecimiento a José y a Simeón. No parece que ninguna cabeza sea femenina, pero desde luego José se hace bien presente en la escena, un tanto meditabundo, pero joven, a tono con la humanista humanización que hay en las todas las figuras" ${ }^{40}$. De ella cabe indicar también que ambas nos recuerdan a las figuras que aparecen en la Virgen del Rosario con dominicos que conserva el Kunsthistoriches Museum de Viena, pintada por Caravaggio para la iglesia de Santo domingo de Nápoles, que fuera grabada por Lucas Vostermans (15951675), mientras que esas dos cabezas dialogantes a la entrada de la cueva están inspiradas copiadas, podría decirse- de las que aparecen en la ilustración del mismo asunto de la Biblia Políglota de 1583, obra que Martínez utilizó con cierta frecuencia para recrear sus composiciones.

Sea como fuere, frente a las Adoraciones de Castillo y Saravia, que podríamos considerar por entonces "de moda" en la ciudad, Martínez realizó una puesta mucho más heterodoxa en composición, y más lumínica en concepto estético, en línea con el concepto "noche", para lo que utilizó perfectamente su conocida técnica del "anieblado", en relación a las "acartonadas" figuras de las tradicionales Adoraciones locales de raigambre zurbaranesca.

\section{Posturas retardatarias: Juan de Guzmán y Juan de Alfaro}

Además de las obras estudiadas, que conformarían el gusto predominante en la ciudad, Córdoba conoció también propuestas provenientes de otros ámbitos, fundamentalmente andaluces, aunque aquí nunca habrían llegado obras de los grandes maestros de este momento, -como Murillo desde Sevilla, o Alonso Cano desde Granada-, lo que dotaría a la pintura barroca cordobesa de cierto carácter endogámico, confiriéndole personalidad propia.

Entre las relacionadas con Sevilla, se encontraría la Adoración (159 x 292 cm.) de Sebastián Gómez el mulato (Hac.1646- Hac.1700), que se conserva en el Museo de Bellas Artes de

40 Galera Andreu, 2017: 247. 
Córdoba desde la Desamortización, haciendo pareja con una Epifanía de idénticas dimensiones. Ambas proceden del antiguo convento de San Jerónimo de Valparaíso, en cuya iglesia habrían campeado. La atribución resulta verosímil, como lo probaría su comparación con la Sagrada Familia de influencia canesca que se conserva en el Museo Nacional de San Carlos de México; o con la Virgen del Rosario del Bellas Artes de Sevilla ${ }^{41}$. Debieron de haber llegado a Córdoba hacia 1670, una vez consolidada en Sevilla la fama de este maestro, que dedicó gran parte de su producción al comercio iberoamericano.

Mientras, los pintores locales de segunda fila seguían realizando Adoraciones, fundamentalmente en base de la copia directa de estampas. Tal fue el caso de Juan de Guzmán, el pintor pontanés ingresado en la orden del Carmelo, llamado en vida religiosa Fray Juan Santísimo Sacramento (Hac.1611-1680), que en sus dos conocidas, -una en la Iglesia de San José y San Cayetano de carmelitas descalzos de Córdoba (214 x $155 \mathrm{~cm}$.) y otra de similares medidas y composición en su homóloga de Lucena -, mostró poca inventiva, copiando de manera literal el grabado de Lucas Vosterman realizado en 1620 para reproducir la famosa composición de Rubens conservada en el Museo de Rouen ${ }^{42}$. Lo que viene a poner de manifiesto que, a partir de1670, la afición por Bloemaert, esencialmente naturalista y empirista, sería progresivamente neutralizada por la obra de Pedro Pablo Rubens, más teatral y expresiva. En lo que tuvieron mucho que ver las versiones de sus Adoraciones realizadas por Vosterman y Bolswert, más acordes con los nuevos gustos teatrales y expresivos que desembocarían en el delirio rococó.

Relacionado con este segundo grabador, y como procedente del primitivo depósito de Capuchinos de la Desamortización, el Museo de Bellas Artes de Córdoba guarda también otro lienzo $(162$ x $207 \mathrm{~cm})$, todavía en pésimo estado de conservación. Siempre citado como anónimo, en 1985 fue sometido a un primer procedimiento de conservación preventiva por empapelado, que le fue retirado en 2007 , dejando ver que se trataba de una copia del grabado de 1620 hecho por Vostermans, que reproduce una nueva composición de Rubens, ésta para la Iglesia de San Juan de Malinas, pintada por el flamenco en 1617. No sería una obra significativa, de no ser porque se puede ver en ella cierta relación con el estilo de otro importante pintor cordobés como lo fue Juan de Alfaro y Gámez (1643-1680), el discípulo cordobés de Velázquez, pudiéndose poner en relación con otro dibujo del propio Museo que aparece firmado y fechado en 1677. (Fig.14)

Por lo demás, no ha podido salir del anonimato el lienzo que guarda el actual IES Luís de Góngora (182 x 120,5 cm.) como perteneciente a la ex-capilla del Colegio de la Asunción. Una pieza que vuelve a partir del conocido grabado de Bloemaert, tomando de él los elementos que le interesan para adaptarse a su formato vertical, para interpretar la zona de gloria a la manera del artista flamenco. Debió de realizarse hacia 1710-20, tras la remodelación de la mencionada capilla, que supuso la intervención en el retablo mayor de Pedro Duque Cornejo (1678-1757) para efigiar a la titular. Los nuevos rectores del Colegio debieron de dejar entonces a un lado la que ya poseía el centro y antes estudiamos, muy probablemente encargada en 1630 a Francisco de Zurbarán por el padre jesuita Martín de Roa, su entonces mandatario.

De la misma fuente grabada habría partido el medio punto anónimo $(169$ x $167 \mathrm{~cm}$.) de procedencia ignorada que guarda el Museo de Córdoba, tras ser adquirido o depositado en el mismo ya en el siglo $\mathrm{XX}^{43}$. Refleja un modelo que llegó a ser repetido en más de una ocasión por los talleres cordobeses a partir del reinado de Carlos II, como demostraría el lienzo existente en la parroquia de Santa Marina de Aguas Santas de Villafranca de Córdoba, del que sabemos que se realizó hacia 1730 para el ático del retablo mayor de la iglesia del convento de San Francisco de la capital.

Igualmente sucederá con en el lienzo anónimo que, perteneciente a la iglesia del antiguo convento de la Trinidad Calzada (190 x $145 \mathrm{~cm}$.), ha pasado a formar parte de la colección

\footnotetext{
41 Sobre estas dos obras véase, Pérez Sánchez, 2000: 72-73.

42 Véase sobre ellas, Quesada,1997: 95. Gavilán Jiménez, 1991: 450.

${ }^{43}$ Sobre él véase Palencia Cerezo, 2001: 108.
} 


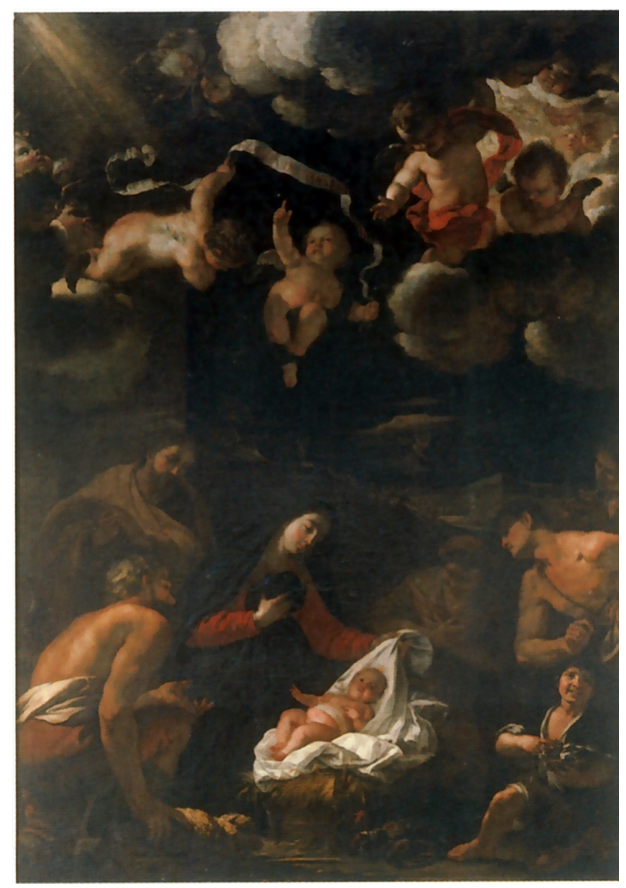

Fig. 15. Acisclo Antonio Palomino. Adoración. Madrid. Consejo de Estado.

instalada en el Centro Carmen Márquez de la Parroquia de San Juan y Todos los Santos ${ }^{44}$. Su dependencia de la estampa de Bloemaert fue establecida por Navarrete ${ }^{45}$, presentando la rareza de haber convertido al pastor situado en su centro en el retrato de un trinitario, sin duda comitente de la pieza.

\section{Las Adoraciones de Palomino}

Al contrario que Francisco Pacheco en su Arte de la pintura, Acisclo Antonio Palomino (1655-1726) no se habría referido explícitamente a la temática, ni dado instrucciones precisas para abordarla en su Museo pictórico y escala óptica, a pesar de lo cual la efigiaría en diferentes ocasiones. No obstante, frente a la creatividad mostrada por su admirado maestro Castillo, se limitaría a plasmarla de dos o tres maneras distintas, repitiéndolas cada vez que la ocasión se le presentaba.

Fuera de lo que pudieran ser claras réplicas de Castilo, es decir, obras que toman elementos presentes en otras pinturas de este maestro efectuadas en sus primeros momentos, la concreción específica más antigua de Palomino tal vez sea la que se encuentra depositada por el Museo Nacional del Prado en el Consejo de Estado, originaria del convento madrileño conocido como las Mercedarias de don Juan de Alarcón $(292 \times 206 \mathrm{~cm})^{46}$. Debió de ser pintada en sus primeros momentos de definitivo asentamiento madrileño, es decir, hacia 1680, y aunque en ella resuenan todavía los ecos de Castillo, podemos considerarla inserta en su nueva etapa de "encaje en el manierismo", como la definieron Bernier Luque y Aguilar Priego. (Fig.15)

En esa ocasión, Palomino planteó la escena bajo un gran arco de arquitectura por el que penetra un rompimiento de gloria, más una iluminación en forma de "y" griega de doble foco lumínico procedente de lo alto, que avanza, centralizado, hacia el Niño. La referencia a Castillo está presente en el pastorcillo que, en la zona inferior derecha, lleva un plato con pichones, como aparecía en el cuadro de 1651 del Museo de Asturias. O también, en el joven

44 Moreno Cuadro, 1994: 105.

45 Véase Navarrete Prieto, 1988: 170. A pesar de ello, a la misma se ha referido el profesor Valiñas afirmando que copia una estampa manierista de origen nórdico. Valiñas López, 2005: 338.

${ }^{46}$ Sobre esta obra véase, por ejemplo, lo apuntado por Gaya Nuño, 1981: 99. Bernier Luque /Aguilar Priego, 2000: 81. Valiñas López, 2005: 345. 
pastor que transporta un tamboril, como en la obra del Museo de Málaga, donde aparecía por primera vez la supuesta vieja partera, que sin embargo, aquí Palomino no introducirá. Por lo demás, determinados elementos de la composición recuerdan también al clásico grabado de Bloemaert tantas veces citado.

Hace unos años, Natividad Galindo dio a conocer una pareja de obras $(81 \times 60 \mathrm{~cm}$.) de Palomino, donde se representa la Adoración de los pastores y la Exifanía, que no dudó en relacionar con el anterior lienzo ${ }^{47}$. Más que de bocetos preparatorios, como ella los entiende, para nosotros ponen de manifiesto la apuesta del pintor por los formatos medios con destino a ámbitos privados. Sea como fuere, del éxito de esta composición nos habla también, por ejemplo, la copia existente en una colección privada $(38,5 \times 30 \mathrm{~cm}$.), que pasó como supuesto original por el comercio madrileño a través Abalarte Subastas, en 12 de diciembre de 2015.

Sin embargo, con el correr de los años y la completa difusión de su fama en toda España, el bujalanceño iba a realizar una nueva composición de pastores que parece que tuvo mayor repercusión, y que utilizaría, tanto para plantearla de manera individual, -como sucede en el cuadro que firmó para la parroquia de Alcocer (Guadalajara)-, como para su inclusión en las diferentes y numerosas series sobre la vida de Cristo, o de la Virgen, que a partir de 1700, distribuyó por distintos establecimientos religiosos españoles ${ }^{48}$. Dentro de este segundo apartado debe ser incluida $(80 \times 100 \mathrm{~cm}$.) la que pertenece a la cordobesa parroquia de San Juan y todos los Santos (Trinidad), -expuesta actualmente en el Centro Parroquial Carmen Márquez-, que fue estudiada por la profesora Raya considerándola original ${ }^{49}$. En ella, Palomino va a fusionar de manera clara el asunto del Anuncio con el de la Adoración, planteando la escena con una luz que penetra desde arriba por la izquierda, delante de una cueva por la que asoma la cabeza del buey y un pastor. San José queda genuflexo por ese lado, delante de una pastora de avanzada edad que porta entre sus manos un cordero, deviniendo una de sus variantes más notables. En primer plano, por la derecha, un aguerrido pastor se yergue semigenuflexo con el torso desnudo. Resuena de nuevo el eco de los grabados manieristas flamencos, no siendo para él baladí que hagamos referencia a otra estampa de Jan Müller (1571-1628), de hacia 1600, que difundió la famosa Resurección de Lázaro de Abraham Bloemaert, hoy conservada en la Alte Pinakotek de Munich; sin que tampoco pueda descartarse cierta influencia de los grabados franceses de la segunda mitad del siglo XVII.

De igual suerte, la profesora Raya dio a conocer otra composición de Palomino (43 x 65 $\mathrm{cm}$.) casi idéntica a la anterior, perteneciente a una serie sobre la vida de la Virgen, que existe en el templo de San Rafael del Juramento ${ }^{50}$. Por su parte, el profesor Valiñas ha notado en ella la influencia de la efectuada por Lucas Jordán para las Descalzas Reales, afirmando que "fue pintado hacia 1713, tal vez, por el mismo tiempo que el artista está en su tierra renovando los cuadros del gran retablo de la Catedral", lo que resulta a medias erróneo, ya que eso cuadros no fueron pintados en Córdoba, sino enviados desde Madrid. A tenor de ello, parece más lógico adelantar su factura en unos años, para llevarla hacia 1705, cuando se encuentra en la ciudad tratando de granjearse a la Inquisición con los cuadros de El Salvador y Santa Ana adoctrinando a la Virgen, que donaría voluntariamente al convento de San Francisco.

Sin embargo, como demuestran las obras de sus últimos años, Palomino habría entrado en un nuevo proceso clasicista; lo que se percibe claramente en la última obra de la temática que de él conocemos. Se trata de la Adoración de Nalvalcarnero (Madrid), realizada a partir de 1723, cuando pide permiso al rey para ir a esa población ${ }^{51}$. Para el templo principal de esta villa, donde ya había intervenido anteriormente en el retablo de la Virgen del Rosario, realizó tres pinturas murales en sus nuevas bóvedas encamonadas, con los temas de la Anunciación,

\footnotetext{
${ }^{47}$ Galindo San Miguel, 2007.

48 Sobre el cuadro de la parroquia de Alcocer, véase Gaya Nuño, 1981:101.

${ }^{49}$ Raya Raya, 1986.

${ }^{50}$ Raya Raya, 1986. Ésta segunda reproducida y estudiada también por Quesada, 1997:117-118.

51 Véase sobre ella Blanco Mozo, 2008 y Valiñas López, 2005: 344.
} 
la Epifania y la Adoración de los pastores. De ellas hoy solo quedan dos, ambas bajo sospecha de repintes y tal vez también de ejecución por algún discípulo, al que, en todo caso, él habría facilitado el programa iconográfico.

En esta ocasión última, para situar la escena, Palomino cambió la pétrea cueva anterior por una edificación de arquitectura de sillares; sustituyendo también por cabezas de querubes lo que eran ángeles de cuerpo entero en la zona de gloria. Cambió también a San José por un pastor arrodillado junto a un cordero maniatado; y a la anterior pastora con cordero, por otra con un cántaro apoyado sobre la parte superior de la espalda. Por la derecha, permutaría por San José al pastor que salía de la cueva, mientras que el pastor en escorzo del primer plano derecho sería también sustituido por otra pastora anciana y arrodillada junto al cesto de pañales.

\section{Conclusión}

Como se habrá podido notar a lo largo de estas apretadas líneas, salvo en algún caso concreto y en las obras derivadas de la actividad de Ribera, la pintura barroca cordobesa generó una imagen de la Natividad del Señor acorde con las primeras representaciones españolas postridentinas, en las que uno de los pastores se arrodillaba ante Jesús, -como en el caso de Melchor en las Epifanías-; un segundo solía permanecer semiprosternado en actitud de adoración, -como Gaspar-; mientras un tercero, cayado en mano, solía portar un cordero a los hombros, quitándose el sombrero con la mano izquierda.

A pesar de las dificultades que se presentan para poder analizar los fondos de arquitectura, y en general el paisaje, por la actitud claroscurista de los artistas y la suciedad que todavía presentan algunas de las obras estudiadas, se pueden establecer dos influencias fundamentales. Por un lado la de Pedro Orrente, concretamente de sus composiciones para la catedral de Toledo ${ }^{52}$ y el convento franciscano de Yeste, que por derivación, introducirán también aquí el naturalismo de corte veneciano. Por otro, el grabado de Boecio Bolswert estampado en 1618, que llevará a la plancha la famosa composición de Abraham Bloemaert de 1614, hoy conservada en el Museo del Louvre, cuya influencia no habría desaparecido nunca. Ello supondría también que, de alguna manera, el influjo de corte manierista se diera de manera constante, llegando hasta Palomino.

En cuanto al lugar donde se desarrolló el nacimiento de Jesús, por lo general y debido a lo anteriormente dicho, el ubi no suele hacerse muy evidente en la pintura barroca cordobesa. En general, no se presentará casi vestigio alguno de cueva labrada por la naturaleza. En cambio, sí existirá siempre fuerte presencia de elementos arquitectónicos, que hablan de un lugar construido por el hombre, generalmente en forma de cobertizo, muy posiblemente situado junto a la puerta de una muralla semiderruida que aludiría a Belén. El divino Salvador yacerá casi siempre en un lecho de paja, no faltando tampoco la presencia de una columna, que simboliza su condición de eje primordial del futuro devenir de la humanidad. Y finalmente, tampoco se decantará de forma unánime por delatar la presencia del buey y la mula, que no siempre serán retenidos en un establo, dándose especial protagonismo normalmente al buey, lo que puede indicar también una mayor importancia simbólica de lo masculino sobre lo femenino.

52 Para el ámbito toledano véase Angulo Iñiguez/Pérez Sánchez, 1972. Revenga Domínguez, 2001 y Revenga Domínguez, 2016: 145-154. 


\section{Bibliografía}

Angulo Íñiguez, D.: Pintura española del siglo XVII, Colección Ars Hispaniae, Plus Ultra, Madrid. (1971).

Angulo Íñiguez, D. y Pérez SánchezA.E.: Pintura toledana. Primera mitad del siglo XVII, C.S.I.C., Madrid. (1972).

Arteaga, Sor Cristina de la Cruz: "El Museo Conventual de Santa Paula en Sevilla". En: Boletin de Bellas Artes, VII, $2^{a}$ Epoca, Sevilla, Real Academia Santa Isabel de Hungría, (1979), pp.103-119.

AA.VV: Antonio del Castillo y su época, catálogo de la exposición, Córdoba, Excma. Diputación. (1986).

AA.VV.: Pintura mejicana, pintura española, de los siglos XVI a XVIII, catálogo de la exposición, Palacio de Bellas Artes de Mexico D.F., México. (1991).

AA.VV.: De Velárquez a Murillo. El siglo de oro en Andalucia, catálogo de la exposición, Fundación Giorgio Cini, Venecia. (1993).

Bernier Luque, J. / Aguilar Priego, R.: "Acisclo Antonio Palomino". En: Cuadernos del Ayuntamiento de Bujalance, 12, Córdoba. (2000).

Blanco Mozo, J. L.: "Antonio Palomino en Navalcarnero". En: Anuario del Departamento de Historia del Arte, XX, Universidad Autónoma, Madrid, (2008), pp.7-18.

Cuéllar Contreras, F. de P.: "Maestros pintores de la escuela sevillana del siglo XVII. Nuevas aportaciones documentales (1).Juan de las Roelas, Antonio Pérez, Francisco Pacheco, Pablo Legot, Andrés Ruiz de Saravia”. En: Revista de Arte Sevillano, 2, Sevilla, (1982), pp.1719.

Delenda, O.: Francisco de Zurbarán (1598-1664). Catálogo razonado y crítico, Madrid. Fundación de Apoyo a la Historia del arte Hispánico. (2010).

Finaldi, G.: José de Ribera. Dibujos. Catálogo razonado, Madrid, Museo Nacional del Prado. (2016).

Galera Andreu, P. A.: "Ficha de la obra El nacimiento de Cristo, de Sebastián Martínez". En: Galera Andreu, Pedro A. / Serrano Estrella, Felipe (Coord.) (2017): Sebastianus. Pintor de Jaén. Sebastián Martinez. Domedel (Jaén, 1615-1667), catálogo de la exposición, Jaén, Instituto de Estudios Giennenses, (2017), pp.247-248.

Galindo San Miguel, N.: "A propósito de dos bocetos de Antonio Palomino”. En: In sapientia libertas. Escritos en homenaje al profesor Alfonso E. Pérez. Sánchez, Madrid, Museo Nacional del Prado Sevilla y Fundación Focus-Abengoa, (2007), pp.566-570.

García de la Torre, F. / Raya Raya, Ma Á.: “La pintura del siglo XVII en Córdoba”. En: Maestros barrocos andaluces, catálogo de la exposición, Museo e Instituto Camón Aznar, Zaragoza, (1988), pp. 47-59.

García de la Torre, F. / Navarrete Prieto, B.: Antonio del Castillo en la senda del naturalismo, catálogo de la exposición, IV Centenario Antonio del Castillo, Córdoba, Junta de Andalucía. (2016).

Gavilán Jiménez, M.: "Fray Juan del Santísimo Sacramento. Nuevos datos sobre su obra". En Aranda Doncel, Juan (Coord.) (1991): II Encuentros de Historia Local. La Campiña, II, Córdoba, Excma. Diputación Provincial, (1991), pp. 447-465.

Gómez Frechina, J.: "Ficha de la obra Adoración de los pastores, de José de Ribera". En: Del Pontormo a Murillo. Entre lo sagrado y lo profano, catálogo de la exposición, Museo de San Carlos, México, (2017), pp.10-11.

Lafuente Ferrari, E.: Breve historia de la pintura española, Madrid, 1953. 
Luque Carrillo, J.: “Obras en el Convento de Santa Isabel de los Ángeles de Córdoba durante el reinado de Felipe II (1556-1598)". En: Peláez del Rosal, Manuel (Coord.) (2016): Congreso Internacional El mundo del Barroco y el Franciscanismo, Baeza - Priego de Córdoba, Universidad Internacional de Andalucía y Asociación Española de Estudios Franciscanos, (2016), pp.108-119.

Moracchini, G.: "Un chef - d'oeuvre de l'ecole de Séville probablement de Zurbaran conservé dans L'eglise de Campana". En Études Corses, LXXVII, 13, Sociéte des Sciences Historiques et naturalles de la Corse, Córcega, (1957), pp.35-42.

Moreno Cuadro, F.: Iconografía de la Sagrada Familia, catálogo de la exposición, Córdoba, Cajasur. (1994).

Nancarrow, M. / Navarrete Prieto, B.: Antonio del Castillo, Madrid, Fundación de Apoyo a la Historia del Arte Hispánico. (2004).

Navarrete Prieto, B.: La pintura andaluza del siglo XVII y sus fuentes grabadas, Madrid, Fundación de Apoyo a la Historia del Arte Hispánico. (1998).

Navarrete Prieto, B.: El papel del dibujo en España, catálogo de la exposición, Madrid, Caylus y Artur Ramon. (2006).

Navarrete Prieto, B. / Pérez Sánchez, A. E.: Álbum Alcubierre. Dibujos. De la Sevilla ilustrada del conde del Aguila a la colección Juan Abelló, Madrid, Fundación de Apoyo a la Historia del Arte Hispánico. (2009).

Német, I.: El Greco, Velárquez, Goya, catálogo de la exposición, Szepmuveszeti Museum, Budapest. (2006).

Ortiz Juárez, D.: "La Adoración de los pastores, de José de Sarabia”. En: Córdoba, 23 de diciembre. (1960).

Ortiz Juárez, D: "El tema de la Navidad en el Museo cordobés. La Adoración de los pastores de José de Ribera”. En: Córdoba, 24 de diciembre. (1961).

Palencia Cerezo, J. M.: "La estela de Zurbarán en la pintura barroca cordobesa”. En: Goya, 275, (2000), pp.67-80.

Palencia Cerezo, J. Ma.: "La adoración de los pastores como tema franciscano y su evolución en la pintura cordobesa. Una aproximación al eslabón perdido de los Sarabia". En: Peláez del Rosal, Manuel (Coord.) (2001): V y VI Curso de Verano (I) El Franciscanismo en Andalucía, Córdoba, (2001), pp. 101-121.

Palencia Cerezo, J. M $\mathrm{M}^{\mathrm{a}}$ : "La pintura barroca cordobesa y Antonio del Castillo: nuevas perspectivas de estudio". En Revenga Domínguez, Paula y Palencia Cerezo, José María (2016): Antonio del Castillo en la ciudad de Córdoba, catálogo de la exposición, IV Centenario Antonio del Castillo, Córdoba, Junta de Andalucía, (2016), pp.85-101.

Palencia Cerezo, J. Ma.: "Sebastián Martínez y Córdoba". En: Galera Andreu, Pedro A. y Serrano Estrella, Felipe (Coord.) (2017): Sebastianus. Pintor de Jaén. Sebastián Martinez. Domedel (Jaén, 1615-1667), Catálogo de la exposición, Jaén, Instituto de Estudios Giennenses, (2017), pp.59-112.

Pérez Lozano, M.: "La pintura en el antiguo Convento". En: Villar Movellán, Alberto (Dir. Cientif.) (1997): El Convento de dominicas del Corpus Christi de Córdoba (1609 - 1992), Córdoba, Cajasur. (1997).

Pérez Sánchez, A. E.: "Exposición de Antonio del Castillo en Córdoba". En: Archivo Español de Arte, 239, (1987), pp.395-396.

Pérez Sánchez, A. E.: Pintura Española en el Museo Nacional de San Carlos, México, catálogo de la exposición, Valencia. (2000). 
Pérez Sánchez, A. E.: Pintura barroca en España (1600-1750), Madrid, 1992. Ponz, Antonio (1792): Viage de España, Tomo XIII- Córdoba. (2010).

Quesada, L.: La Navidad en el arte: pinturas de Iglesias y Museos de Andalucia, Sevilla, Fundación Sevillana de Electricidad. (1997).

Raya Raya, M A.: "Acisclo Antonio Palomino: otras obras". En: Apoteca, Universidad de Córdoba, Departamento Historia del Arte, (1986), pp. 39-57.

Revenga Domínguez, P.: Pintura y pintores toledanos de la segunda mitad del siglo XVII, Fundación Universitaria Española, Madrid. (2001).

Revenga Domínguez, P.: “El Greco a Toledo, 1577”. En: Puppi, Lionello (ed.): El Greco in Italia. Metamorfosi di un Genio. Saggi, Skira, Milán, (2016), pp. 145-156.

Sánchez-Mesa Martín, D.: El Arte del barroco, Tomo VII de la Historia del Arte de Andalucía, Gever, Sevilla, 1991.

Valiñas López, F. M.: La Navidad en las artes plásticas del barroco español. Tesis doctoral dirigida por D. Domingo Sánchez-Mesa Martín, Universidad de Granada. (2005).

Valverde Madrid, J.: "Dos pintores sevillanos en Córdoba: Sarabia y Valdés Leal". En: Archivo Hispalense, 38-39, Sevilla, (1963), pp. 9-60.

Zueras, F.: "Lienzos de Navidad. La Natividad en la pintura barroca cordobesa". En: Córdoba, jueves 24 de diciembre. (1987). 